UNIVERSIDADE DE SÃO PAULO

Instituto de Astronomia, Geofísica e Ciências Atmosféricas

\title{
ESTUDO DAS VARIAÇÕES DIURNAS DE RADIAÇÃO GAMA ATMOSFÉRICA E SUA INTERFERÊNCIA EM LEVANTAMENTOS DE ESPECTROMETRIA GAMA AEROTRANSPORTADA
}

FABIANO DELLA JUSTINA 


\section{ESTUDO DAS VARIAÇÕES DIURNAS DE RADIAÇÃO GAMA ATMOSFÉRICA E SUA INTERFERÊNCIA EM LEVANTAMENTOS DE ESPECTROMETRIA GAMA AEROTRANSPORTADA}

FABIANO DELLA JUSTINA

Dissertação corrigida da original apresentada ao Instituto de Astronomia, Geofísica e Ciências Atmosféricas da Universidade de São Paulo para a obtenção do título de mestre em geofísica. A versão original encontra-se na biblioteca do Instituto.

Orientador: Prof. Dr. Fernando Brenha Ribeiro 


\section{AGRADECIMENTOS}

Ao programa de Pós-graduação em Geofísica do IAG-USP pela oportunidade;

Ao Prof. Dr. Fernando Brenha Ribeiro, pela orientação e sugestões sempre oportunas;

A minha esposa Janaina pela paciência, compreensão e companheirismo;

À Capes, pela bolsa de estudos concedida em meu primeiro ano do mestrado;

À Companhia Baiana de Pesquisa Mineral principalmente ao geólogo MsC. Ives Garrido, pela disponibilização dos dados utilizados nesse trabalho.

Ao Instituto Nacional de Meteorologia pela disponibilização dos dados meteorológicos referentes à estação de Vitória da Conquista.

À Prospectors Aerolevantamentos e Sistemas LTDA, pela disponibilização da licença do software Oasis Montaj.

Ao Geólogo Rodrigo H. Sternert pelas discussões e informações sempre relevantes;

Aos ex-colegas de trabalho Álvaro, Luis Otávio, Edmilson e Waldyr pelo auxílio na compilação de informações;

Aos colegas de sala Victor e Helen pelo companheirismo;

Aos colegas do IAG, pela amizade e apoio ao longo do curso;

Ao técnico Roberto Zanon pelas discussões sempre interessantes;

À minha família pelos incentivos, motivação e amizade;

Aos meus Sogros pelo carinho;

À todos aqueles que diretamente ou indiretamente contribuíram para o desenvolvimento do trabalho. 


\section{SUMÁRIO}

1. INTRODUÇÃO

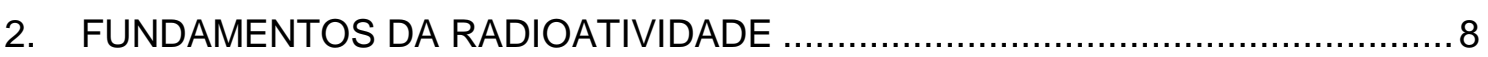

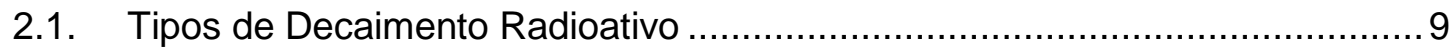

2.2. Natureza Estatística dos Decaimentos Radioativos ………………….........10

2.3. Desequilíbrio Radioativo .................................................................. 12

2.4. Fontes Naturais de Radiação ............................................................. 13

2.5. Interação da Radiação Gama com a Matriz ..............................................13

3. ESPECTRÔMETRO DE IODETO DE SÓDIO ATIVADO À TALIO_.......................15

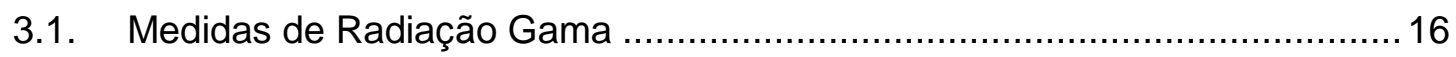

3.2. Modelo Teórico para Gamaespectrômetros Aerotransportados ......................17

4. RADÔNIO EM SOLOS, ROCHAS E NA ATMOSFÉRA. .....................................20

4.1. Emanação e Exalação do Radônio em Solos e Rochas ...............................20

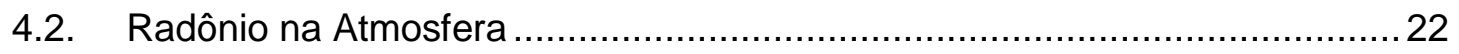

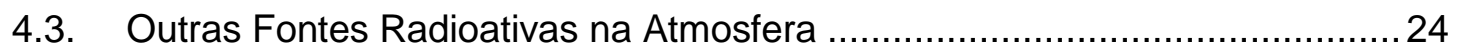

5. REDUÇÃO DAS MEDIDAS DE TAXA DE CONTAGENS PARA

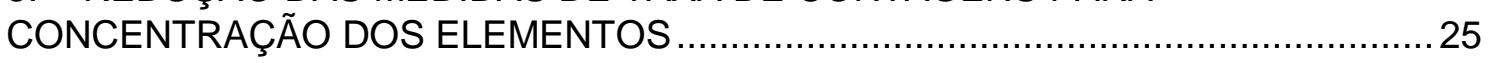

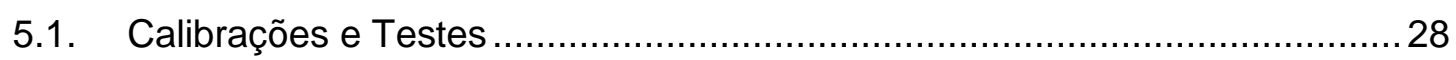

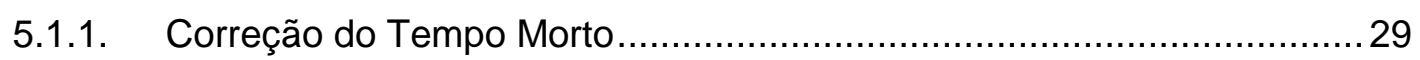

5.1.2. Radiação Cósmica de Fundo e Radiação da Aeronave .......................... 30

5.1.3.1. Método com Detectores Voltados para Cima.......................................35

5.1.4. Calibração com Blocos Radioativos................................................... 45

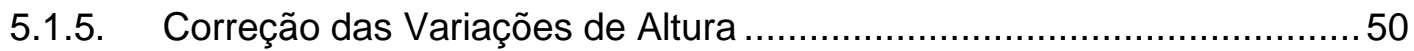

5.1.5.1. Determinação dos Coeficientes de Atenuação Atmosférica.............52

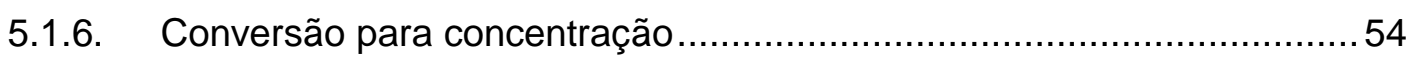

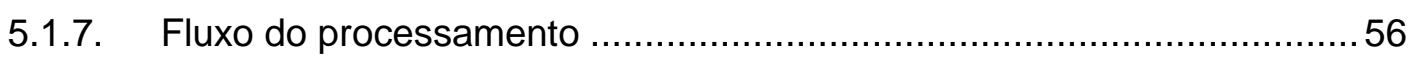

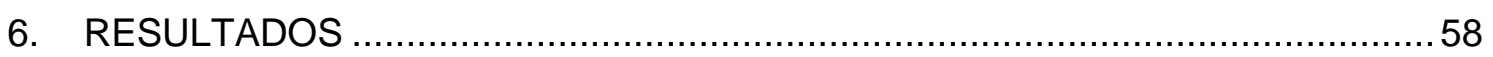

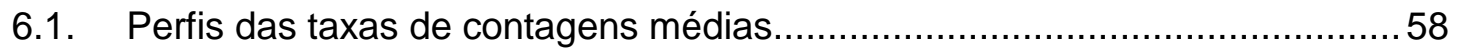

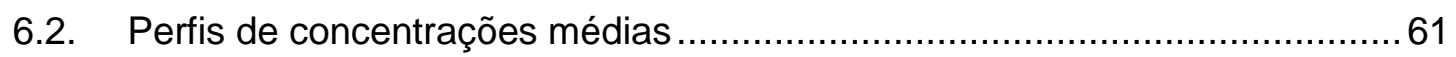

6.3. Perfis comparativos diários de concentração de urânio equivalente ..............67

6.4. Perfil de concentração média de urânio equivalente sem correção de radônio

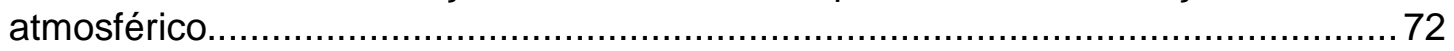

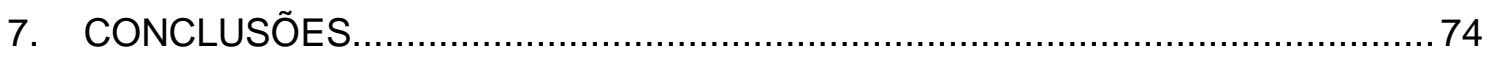

8. REFERÊNCIAS ................................................................................................................. 


\section{LISTA DE FIGURAS}

Figura 3.1 - Espectro de radiação gama ........................................................... 15

Figura 3.2 - Geometria fonte-detector para o modelo duas camadas ........................ 18

Figura 3.3 - Porcentagem de rendimento de uma fonte de radiação infinita ................ 19

Figura 4.1 - Série de decaimento natural do U-238............................................... 21

Figura 4.2 - Efeito da umidade do solo sobre a concentração de radônio ..................... 22

Figura 4.3 - Concentrações calculadas para ${ }^{214} \mathrm{~Pb}$ e ${ }^{214} \mathrm{Bi}$ na baixa atmosfera ............23

Figura 5.1 - Geologia e localização associada à linha de estudo (Linha A-B) ............26

Figura 5.2 - Ajuste para determinação dos coeficientes de radiação cósmica..............31

Figura 5.3 - Espectro de radiação gama indicando a faixa de energia ........................ 33

Figura 5.4 - Variações do espectro associadas à variação do radônio atmosférico....34

Figura 5.5 - Disposição espacial da linha de repetibilidade radiométrica...................... 38

Figura 5.6 - Relação entre os detectores nas janelas do urânio................................. 39

Figura 5.7 - Relação entre a janela do urânio e a do potássio................................... 39

Figura 5.8 - Relação entre a janela do urânio e a do tório..........................................40

Figura 5.9 - Relação entre a janela do urânio e a de contagem total. .......................... 40

Figura 5.10 - Ajuste para determinação do coeficiente de atenuação atmosférica .....53

Figura 6.1 - Perfil da taxa de contagem média referente à janela do urânio. ...............58

Figura 6.2 - Perfil da taxa de contagem média referente à janela do tório...................59

Figura 6.3 - Perfil da taxa de contagem média referente à janela potássio. .................59

Figura 6.4 - Perfil da taxa de contagem média referente à janela de contagem total. . 60

Figura 6.5 - Perfil da taxa de contagem média referente à janela do urânio (upward). 60

Figura 6.6 - perfis comparativos de concentração média de urânio equivalente..........62

Figura 6.7 - perfis comparativos de concentração média de tório equivalente. .............63

Figura 6.8 - perfis comparativos de concentração média de potássio. ...........................64

Figura 6.9 - perfis comparativos de taxa de exposição média...................................65

Figura 6.10 - Perfis comparativos diários de concentração de urânio equivalente. ....69

Figura 6.11 - Perfis comparativos diários de concentração de urânio equivalente ......71

Figura 6.12 - perfil comparativo de concentração média de urânio equivalente ..........73 


\section{LISTA DE TABELAS}

Tabela 3.1 - Janelas de energia de radiação gama....................................... 16

Tabela 4.1 - Faixas energéticas do Gamaespectrômetro .................................. 28

Tabela 5.1 - coeficientes de radiação cósmica e radiação de fundo ................. 32

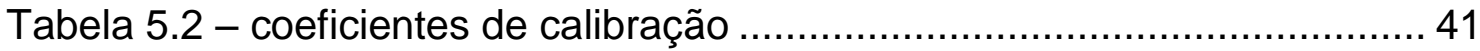

Tabela 5.3 - Coeficientes a1 e a2 determinados.......................................... 45

Tabela 5.4 - concentrações dos tanques de calibração ................................... 46

Tabela 5.5 - Valores dos coeficientes de espalhamento Compton................... 48

Tabela 5.6 - coeficiente de atenuação atmosférica ......................................... 54

Tabela 5.7 - Sensibilidade do sistema....................................................... 55 


\section{RESUMO}

As concentrações de urânio equivalente, tório equivalente, potássio e taxa de exposição foram determinadas em diferentes dias e horários para um mesmo local, a partir de dados gamaespectrométricos aerotransportados, medidos a uma altura média de 81 metros. Os perfis individuais foram então comparados com os perfis médios de todas as medidas. Os efeitos do radônio atmosférico e dos seus produtos de decaimento foram corrigidos com um pacote de cristais detectores extras voltados para cima, e os valores de calibração desses foram determinados a partir dos dados dos testes de radiação gama atmosférica: medidas acima de 760 metros de altura. A influência da radioatividade dos solos e rochas nos detectores voltados para cima foi corrigida de acordo com a técnica desenvolvida por Grasty e Hovgaard (1996) e discutida para as duas situações que elas são propostas. 


\section{ABSTRACT}

The concentration of equivalent uranium, equivalent thorium, potassium and exposure rate were calculated on different days and hours for the same location, from airborne gamma ray spectrometric data, measured at an average height of 81 meters. The individual profiles were compared with mean profiles of all the measurements. The effects of atmospheric radon and its decay products were corrected using a pack of additional detectors crystals facing up ("upward looking" detector), and the calibration values these were determined from test data of atmospheric gamma radiation: measurements above 760 meters in height. The influence of radioactivity in soil and rocks in the "upward looking" detector was corrected according to the technique developed by Grasty and Hovgaard (1996) and discussed the two situations for which they are proposed. 


\section{INTRODUÇÃO}

Gamaespectometria é uma técnica geofísica amplamente utilizada principalmente como apoio ao mapeamento geológico e à exploração mineral. Consiste essencialmente em medir as concentrações dos três principais isótopos naturais: potássio, urânio e tório, associados às primeiras dezenas de centímetros da superfície terrestre, através de medidas de radiação gama (Grasty \& Minty, 1995). A aquisição de dados desta natureza pode ser realizada de duas formas: terrestre ou área (com auxilio de aeronaves). No entanto, ambas estão sujeitas a erros e informações que não necessariamente estão relacionados com a geologia do local a ser estudado. As principais fontes das incertezas são: elementos cosmogênicos que entram na atmosfera, emanação de séries radioativas (principalmente radônio) e o comportamento dessas em função de fatores atmosféricos (Kogan et al, 1971).

Levantamentos gamaespectrométricos aerotransportados são muito importantes por cobrirem grandes áreas, às vezes de difícil acesso e com poucas informações geológicas. No entanto, para determinar as concentrações de urânio, tório e potássio nos solos e rochas a partir de medidas de radiação gama realizadas em equipamentos aerotransportados, é necessária uma série de correções obtidas por meio de testes e calibrações. Este processo pode inserir erros que resultam em valores falsos de concentrações. Uma das correções mais sujeitas ao erro são as correções do radônio atmosférico e produtos do seu decaimento, pois suas concentrações na atmosfera variam em um mesmo dia, entre um dia para outro e ate mesmo de uma estação do ano para outra (IAEA, 1991). 
Para corrigir o efeito do radônio atmosférico dos dados existem alguns métodos. No Brasil utiliza-se um conjunto extra de detectores voltados para cima, com objetivo de medir a radiação gama atmosférica. Porém, para uma correção coerente este conjunto extra deve ser devidamente calibrado (KRAUSZ et al, 2003).

Os objetivos desse trabalho foram: determinar a concentração de urânio equivalente, tório equivalente, potássio e a taxa de exposição para um trecho de $8 \mathrm{~km}$ medido 88 vezes em 43 dias diferentes, em um local onde a variação gama atmosférica variou consideravelmente ao longo dos dias; e avaliar os valores de concentração para cada teste. 


\section{FUNDAMENTOS DA RADIOATIVIDADE}

Átomos são as menores partículas de massa com propriedades químicas distintas. Um átomo consiste de um núcleo cercado por elétrons. $\mathrm{O}$ diâmetro de um átomo é na ordem de $10^{-10}$ metros, do núcleo na ordem $10^{-15}$ metros. Prótons e nêutrons tem uma massa de $1,67 \times 10^{-27} \mathrm{Kg}$ (Gilmore \& Hemingway, 1995).

O numero de prótons no núcleo de um determinado elemento, é também denominado de número atómico $(Z)$ e a soma de prótons e nêutrons o número de massa (A). Átomos de um mesmo elemento tem o mesmo número atómico, mas diferentes números de nêutrons chamados de isótopos. Esses possuem propriedades químicas idênticas, porém propriedades físicas diferentes.

O núcleo atómico de um mesmo isótopo tem um excedente de energia, são instáveis e decaem para formar um núcleo mais estável de um isótopo diferente. Esse processo é acompanhado por uma emissão de partículas de energia denominado radiação nuclear. Nuclídeos com essa características são chamados de radionuclídeos e o processo de decaimento nuclear ou desintegração (Krausz et al, 2003).

O decaimento radioativo diminui o numero de átomos do radionuclídeo com o tempo:

$$
N_{t}=N_{0} e^{-\lambda t}
$$

Onde: $N_{t}=$ numero de átomos presentes após o tempo $t(\mathrm{~s})$;

$$
N_{0}=\text { numero de átomos presentes no tempo } t=0 \text {; }
$$


$\lambda=$ constante de decaimento do radionuclídeo $\left(\mathrm{s}^{-1}\right)$.

Uma relação constante, a meia vida $T_{1 / 2}$ (s), é o tempo para metade da massa do radionuclídeo decair:

$$
T_{1 / 2}=\frac{0,693}{\lambda}
$$

O produto $\lambda N$ resulta na atividade do radionuclídeo. O decaimento radioativo ocorre independente das condições físicas.

\subsection{Tipos de Decaimento Radioativo}

Decaimento alfa é acompanhado por uma liberação de uma partícula alfa que consistem em dois prótons e dois nêutrons. Decaimento beta é realizado pela emissão de uma partícula beta idêntica a um elétron negativamente carregado. $\mathrm{O}$ decaimento beta+ ocorre com menor frequência e é acompanhado pela emissão de um pósitron positivamente carregado. A captura de elétron ocorre através da absorção de um elétron orbital de um átomo por um núcleo atômico. Frequentemente o radionuclídeo instável decai para um estado ainda excitado, e a emissão de partículas (alfa e beta) não é suficiente para que o átomo atinja o estado de equilíbrio ocorrendo então a emissão de energia pura, denominada radiação gama. Essa é constituída de ondas eletromagnéticas com comprimento de onda muito baixo. As ondas eletromagnéticas ou fótons são desprovidos de massa e se propagam através do espaço tempo com a velocidade da luz e suas energias variam consideravelmente (Gilmore \& Hemingway).

O tipo de decaimento de nuclídeos instáveis determina a natureza do novo átomo formado. No entanto, alguns radionuclídeos podem ter mais de um 
modo de decaimento. Por exemplo, $66 \%$ do ${ }^{212} \mathrm{Bi}$ desintegra pela emissão partículas beta para ${ }^{212} \mathrm{Po}$, e $34 \%$ desintegra pela emissão de partícula alfa para ${ }^{208} \mathrm{TI}$. Importante ressaltar que independentemente do tipo de radiação, a meia vida é sempre a mesma (Krausz et al , 2003).

Decaimentos radioativos também podem ocorrer em séries, com um numero de produtos "filhos" que são radioativos e terminam em um isótopo estável. Em um sistema fechado, iniciando com uma quantia específica de elementos "pais", o numero de átomos de elementos "filhos" e sua atividade cresce gradualmente até alcançar o equilíbrio radioativo da série. Nesse ponto, as atividades de todos os radionuclídeos da série são idênticas. Assim a medida da concentração de um elemento "filho" pode ser usada para estimar a concentração de outro elemento "filho" da série. Respeitando as condições de equilíbrio, essas relações podem ser expressas por:

$$
\lambda_{1} N_{1}=\lambda_{2} N_{2}=\ldots \lambda_{i} N_{i}
$$

\subsection{Natureza Estatística dos Decaimentos Radioativos}

Decaimentos radioativos são fenômenos estatísticos. Cada desintegração atômica ocorre completamente independente de outro decaimento radioativo, e o intervalo de tempo entre as desintegrações não são constantes. Para um grande número de desintegrações aleatórias de um determinado radionuclídeo, a frequência do decaimento radioativo é dado por uma distribuição de Poisson (Grasty\& Minty, 1995). Se $\bar{n}$ é a média da taxa de 
decaimento, a propabilidade $P$, que o número do núcleo atômico $n$, decairá por unidade de tempo é:

$$
P(n)=\frac{\bar{n}^{n}}{n !} e^{-\bar{n}}
$$

Para uma distribuição de Poisson isso assegura que a variância $\sigma^{2}$ para uma distribuição é igual ao seu valor da média e $\sigma$ o desvio padrão. Os valores de $\pm 1 \sigma$ sobre a média engloba $68,3 \%$ da distribuição, $\pm 2 \sigma$ engloba $95,5 \%$, e $\pm 3 \sigma$ engloba $99,7 \%$ da distribuição.

A emissão de partículas e raios gama no decaimento radioativo é proporcional ao número de desintegração de átomos; o desvio padrão pode ser usado para estimar o erro das medidas radiométricas (Krausz et al, 2003). Se $N$ contagens são gravadas em um tempo $t$, então $o$ desvio padrão das contagens gravadas é:

$$
\sigma(N)=\sqrt{\bar{N}}
$$

Onde $\bar{N}$ é a media das medidas de contagens.

O desvio padrão para uma medida (erro na medida de N) é:

$$
\frac{\sigma(N)}{\bar{N}}=\frac{1}{\sqrt{\bar{N}}}
$$

Para uma taxa de contagem $n=N / t$, o desvio padrão e dado por:

$$
\sigma(n)=\frac{\sqrt{N}}{t}=\sqrt{\frac{n}{t}}
$$


O "desvio provável" $(\mathrm{P}=0,5)$ é dado por 0,674 $\sigma$. Na pratica, fontes de erros estão mais relacionadas com a radiação de fundo (background) (Kogan et al, 1971).

\subsection{Desequilíbrio Radioativo}

Ocorre quando um ou mais produtos da serie de decaimento são completamente ou parcialmente removidos ou adicionados ao sistema. Tório por exemplo, raramente ocorre fora do equilíbrio na natureza, e não existem problemas com o potássio. No entanto, na serie de decaimento do urânio o desequilíbrio é comum, podendo ocorrer em diversas posições na série. $\mathrm{O}^{238} \mathrm{U}$ pode ser seletivamente lixiviado para o ${ }^{234} \mathrm{U}$, ou vice-versa; $\mathrm{O}{ }^{230} \mathrm{Th}$ e o ${ }^{226} \mathrm{Ra}$ podem ser seletivamente removidos da serie de decaimento; e por último ${ }^{222} \mathrm{Rn}$ que por ser um gás, facilmente escapa dos solos e rochas para a atmosfera. Dependendo das meias-vidas dos radioisótopos envolvidos, pode levar dias, meses ou até milhões de anos para o equilíbrio ser restabelecido.

Desequilíbrio na serie de decaimento do urânio é uma fonte séria de erro em espectrometria de raios gama. Concentrações de urânio são estimadas com base nas medidas da abundância dos isótopos ${ }^{214} \mathrm{Bi}$ e ${ }^{214} \mathrm{~Pb}$, que estão localizados bem abaixo na serie de decaimento, e algumas vezes não estão em equilíbrio com o urânio. Estimativas das concentrações de urânio são geralmente reportadas como "urânio equivalente" (eU), é são determinadas assumindo concentrações de equilíbrio. Tório também é reportado como "tório equivalente" (eTh), entretanto também pode estar em condições de desiquilíbrio (Krausz et al, 2003). 


\subsection{Fontes Naturais de Radiação}

Muitos elementos que ocorrem naturalmente possuem isótopos radioativos, mas somente as séries do urânio, tório e do potássio possuem radioisótopos que produzem raios gama com intensidade de energia suficiente para serem medidas com espectrometria de raios gama, pois são relativamente abundantes no ambiente natural. Médias da abundancia para a crosta terrestre desses elementos são fornecido na literatura: 2-2,5\% de potássio, 2-3 ppm de urânio e 8-12 ppm de tório (Kogan et al, 1971).

O ${ }^{40} \mathrm{~K}$ é o isótopo radioativo do potássio e ocorrem $0,012 \%$ da forma natural do potássio. Esse isótopo decai para ${ }^{40} \mathrm{Ar}$ com emissão de raios gama com energia de $1,46 \mathrm{Mev}$. A meia-vida do ${ }^{40} \mathrm{~K}$ é de $1,3 \times 10^{9}$ anos. Urânio ocorre naturalmente como ${ }^{238} \mathrm{U}$ e ${ }^{235} \mathrm{U}$, que dão origem a série de decaimento que termina com isótopos estáveis, ${ }^{206} \mathrm{~Pb}$ e ${ }^{207} \mathrm{~Pb}$ respectivamente. As meias-vidas do ${ }^{238} \mathrm{U}$ e do ${ }^{235} \mathrm{U}$ são $4,46 \times 10^{9}$ anos e $7,13 \times 10^{8}$ anos. Tório ocorre naturalmente como o radioisótopo ${ }^{232} \mathrm{Th}$, que dá início à serie de decaimento $\mathrm{e}$ termina com o isótopo estável ${ }^{208} \mathrm{~Pb}$. A meia-vida do ${ }^{232}$ Th é de $1,39 \times 10^{10}$ anos. Tanto ${ }^{238} \mathrm{U}$, quanto ${ }^{232} \mathrm{Th}$ não emitem raios gamas, consequentemente a emissão de radiação gama de seus "filhos" é que são utilizadas para estimar suas concentrações (Krausz et al, 2003).

\subsection{Interação da Radiação Gama com a Matriz}

Radiação gama é parte de um espectro eletromagnético. Raios gama viajam com velocidade da luz $(c)$ e tem uma energia discreta $(E)$, frequência $(f)$ e comprimento de onda $(\lambda)$.

$$
E=h f=h c / \lambda
$$


Onde: $h=$ constante de Planck $=6,6261 \times 10^{-34} \mathrm{Js}$.

Acima de $40 \mathrm{KeV}$ de energia no espectro eletromagnético é onde compreende a radiação gama.

Raios gama interagem com a matéria por três principais processos (Krausz et al, 2003): Efeito fotoelétrico, espalhamento Compton e produção de pares. Efeito fotoelétrico é um processo de absorção predominante em baixas energias. Espalhamento Compton predomina em energias moderadas e corresponde a uma colisão de um fóton incidente com um elétron. O fóton incidente perde parte da energia para o elétron e é "espalhado" formando um ângulo com sua direção original. Produção de pares ocorrem em energias maiores que 1,2 MeV. Esse é o processo no qual um fóton incidente, é completamente absorvido e resulta na criação de um par elétron-pósitron no campo eletrostático do núcleo (Krausz et al, 2003). Para raios gama naturais de origem terrestre ( $E$ até $2,615 \mathrm{MeV}$ ) e matéria compreendendo rochas, água e ar, espalhamento Compton é o processo de iteração dominante. 


\section{ESPECTRÔMETRO DE IODETO DE SÓDIO ATIVADO A TALIO}

Consiste em um cintilador e um fotomultiplicador, os fótons de raios gama incidentes interagem com o cristal e produz cintilações. Estes fótons de luz visível induzem à ejeção de elétrons do fotocátodo para o fotomultiplicador e uma nuvem de elétrons atinge o anôdo. Isso induz um pulso negativo de tensão de saída, com amplitude proporcional à energia do fóton incidente (Grasty \& Minty, 1995). Espectrômetros de lodeto de Sódio Ativado a Talio tem uma detecção eficiente para baixas energias, mas uma detecção menos eficiente para altas energias. O "tempo morto" é na ordem de $10^{-7}$ segundos, e a resolução de energia para $0{ }^{137} \mathrm{Cs}$ em $662 \mathrm{Kev}$ com uma faixa de $7-10 \%$, dependendo do volume do detector. Detectores $\mathrm{Nal}(\mathrm{TI})$ são higroscópicos, envelhecem, são frágeis e as propriedades do tubo fotomultiplicador varia com a temperatura (KRAUSZ et al, 2003).

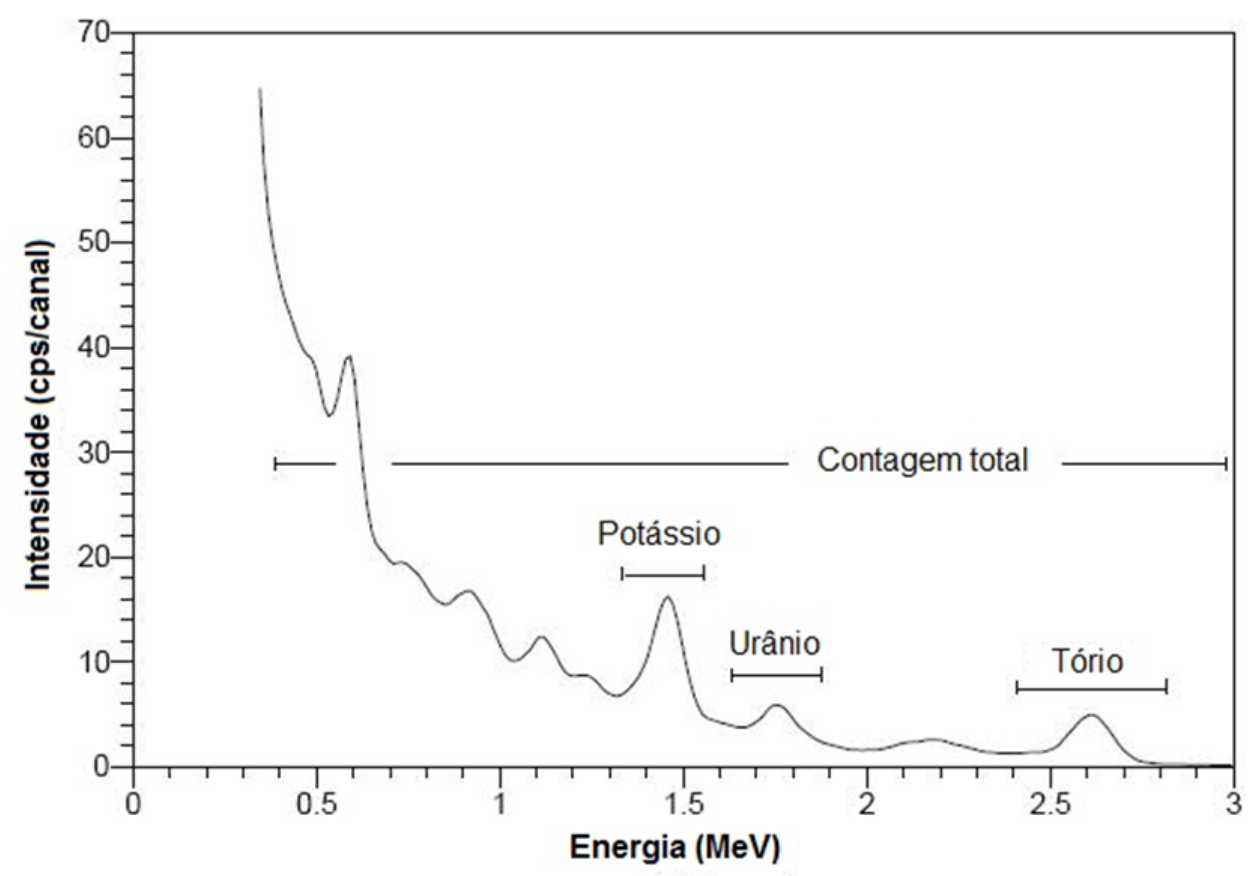

Figura 3.1 - Espectro de radiação gama

(Fonte: Grasty \& Minty, 1995). 
A figura 3.1 apresenta um típico espectro de radiação gama. Para cada radioisótopo há uma "janela" de energia definida.

Na tabela 3.1 verificamos as "janelas" de energia de radiação gama recomendada para mapeamento de elementos radiométricos.

Tabela 3.1 - Janelas de energia de radiação gama recomendadas para mapeamentos de elementos radiométricos

(Fonte: Grasty \& Minty, 1995).

\begin{tabular}{|c|c|c|c|}
\hline Janela & $\begin{array}{c}\text { Isótopo } \\
\text { Usado }\end{array}$ & Energia $(\mathrm{KeV})$ & $\begin{array}{c}\text { Janela de Energia } \\
(\mathrm{KeV})\end{array}$ \\
\hline Potássio & ${ }^{40} \mathrm{~K}$ & 1460 & $1370-1570$ \\
\hline Urânio & ${ }^{214} \mathrm{Bi}$ & 1760 & $1660-1860$ \\
\hline Tório & ${ }^{208} \mathrm{TI}$ & 2615 & $2410-2810$ \\
\hline Contagem Total & - & - & $410-2810$ \\
\hline Cósmico & - & - & $3000-\infty$ \\
\hline
\end{tabular}

\subsection{Medidas de Radiação Gama}

Gamaespectrômetros geralmente gravam as informações em 256, 512 ou 1024 canais, em uma faixa de energia de 0 a 3 MeV. Cada canal grava todos os raios gama absorvidos pelo detector em uma faixa de 11, $7 \mathrm{KeV}$ (256 canais). 


\subsection{Modelo Teórico para Gamaespectrômetros Aerotransportados}

A abordagem mais simples para a modelagem de raios gama para um sistema aerotransportado, é um modelo semiempírico de radiação monoenergética. Clark et al (1972) usaram um modelo de duas camadas: a Terra é um semiespaço infinito com uma densidade constante e com uma certa concentração de radioelementos, recoberto por ar não radioativo de densidade constante (Figura 3.2). Os autores mostram que a intensidade de radiação monoenergética $\mathrm{dl}$, para um fotopico de intensidade energética de raios gama $E_{0}$, por um elemento de volume $d V$ é dada por:

$$
d I=\frac{A \varepsilon}{4 \pi R^{2}} e^{-\mu_{e} r_{e}} e^{-\mu_{a} r_{a}} N d V
$$

Onde: $N d V=$ é o numero de raios de energia $E_{0}$ emitidos por segundo por elemento de volume $d V$;

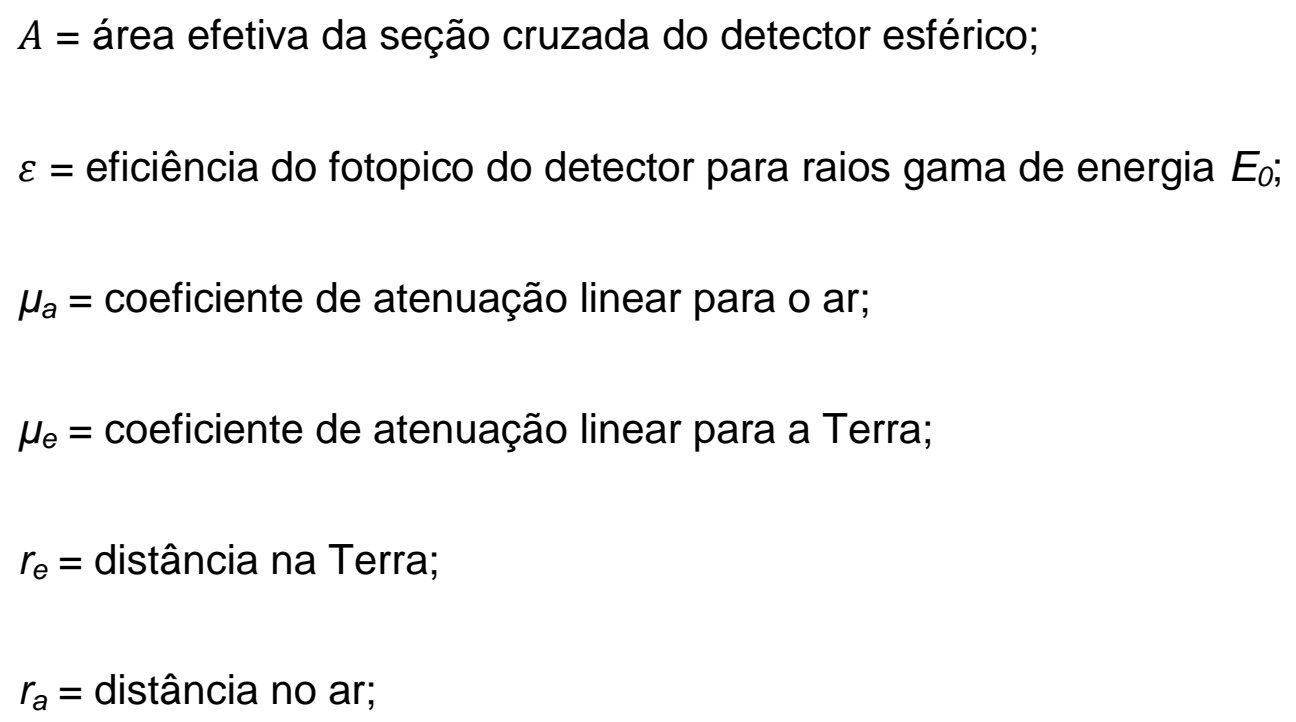




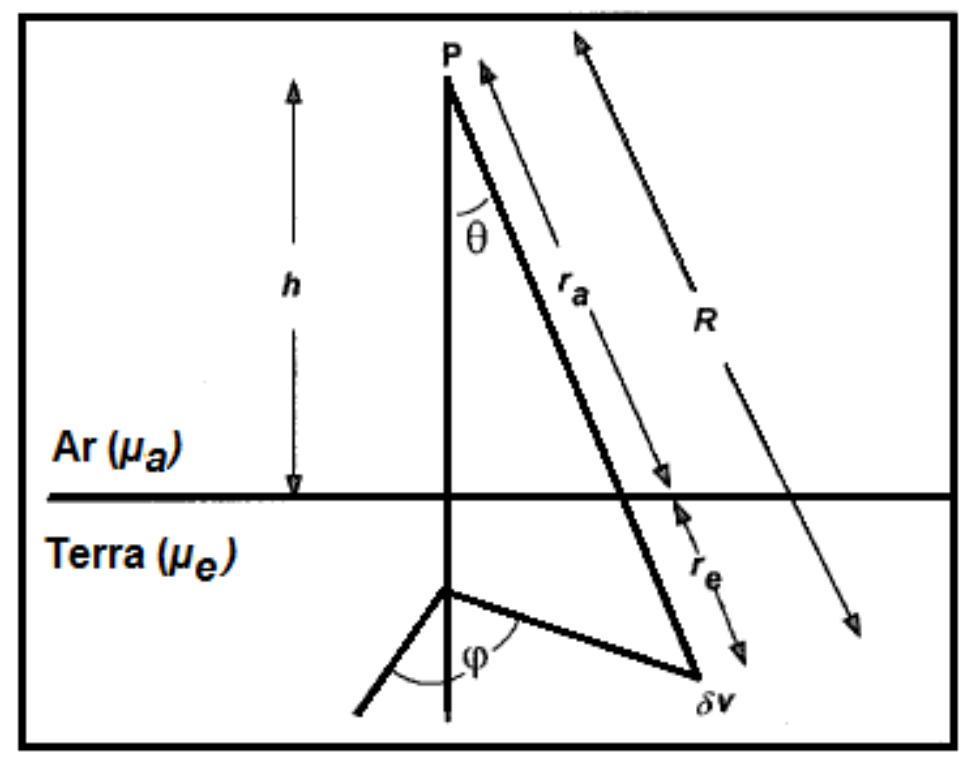

Figura 3.2 - Geometria fonte-detector para o modelo duas camadas "terra-ar" (Fonte: Krausz et al, 2003).

A equação 3.2 pode ser integrada para diversas geometrias fontereceptor obtendo a resposta do fotopico para um determinado tipo de fonte. Grasty (1987) propôs que a radiação devida uma fonte circular pode ser expressa como uma porcentagem da radiação de uma fonte infinita, de acordo com a relação abaixo:

$$
P=100\left|\frac{E_{2}(\mu h)-\cos \varphi E_{2}\left(\frac{\mu h}{\cos \varphi}\right)}{E_{2}(\mu h)}\right|
$$

Onde $h$ é altura do detector, $\mu$ é o coeficiente de atenuação linear dos raios gama no ar, $E_{2}$ é a integral exponencial do segundo meio. A figura 3.3 mostra o percentual de "rendimento da fonte infinita" (equação 3.2) para raios gama de tório $\left({ }^{208} \mathrm{Tl}\right)$ em função do raio da fonte. Um coeficiente de atenuação linear para $\mathrm{o}$ ar de $0,00505 \mathrm{~m}^{-1}$ e um detector a 100 metros foram usados. $\mathrm{O}$ gráfico mostra que quase $40 \%$ dos fótons medidos em uma fonte infinita são 
gerados em uma fonte com raio de 100 metros, e somente $20 \%$ dos fótons são medidos com a fonte acima de 300 metros de raio.

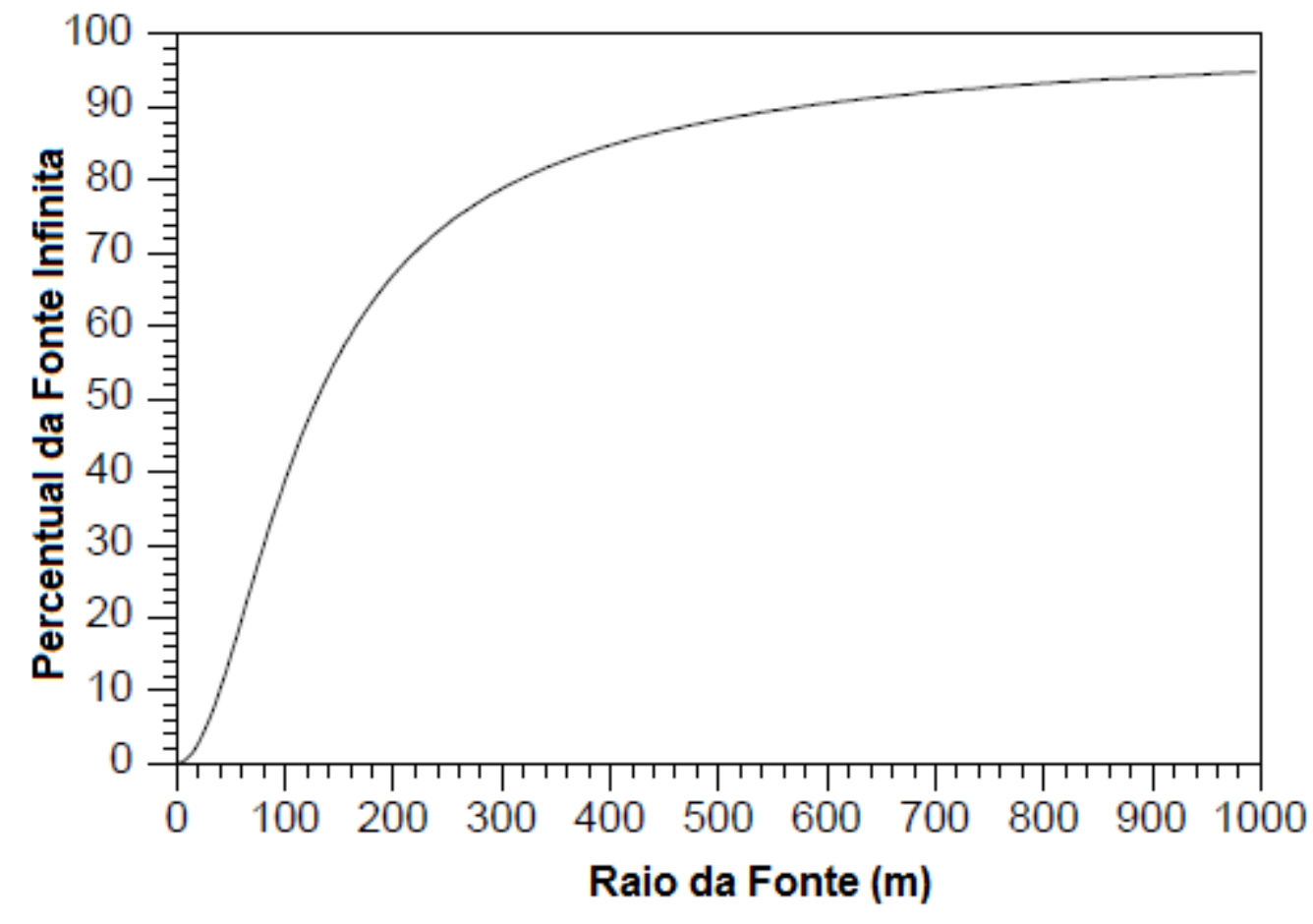

Figura 3.3 - Porcentagem de rendimento de uma fonte de radiação infinita (Fonte: Krausz et al, 2003). 


\section{RADÔNIO EM SOLOS, ROCHAS E NA ATMOSFÉRA.}

\subsection{Emanação e Exalação do Radônio em Solos e Rochas}

.Na série de decaimento do ${ }^{238} \mathrm{U}$ (figura 4.1) o desequilíbrio é muito comum e pode ocorrer em vários momentos da série. No entanto, em levantamentos gamaespectrométricos aerotransportados 0 desequilíbrio ocasionado pela exalação do ${ }^{222} \mathrm{Rn}$ para atmosfera é uma das principais fontes de erro (Grasty \& Minty, 1995).

A taxa de emanação do radônio é um importante parâmetro que indica a sua liberação para a atmosfera (Garver \& Baskaran, 2004). Quando um átomo de ${ }^{226} \mathrm{Ra}$ decai para ${ }^{222} \mathrm{Rn}$ libera $100 \mathrm{KeV}$, mas somente os átomos que estão extremamente na superfície contribuem para emanação de Radônio, segundo Amin \& Rama (1986) 40 nm em minerais e de acordo com Semkow (1990) 35 nm na argila, $95 \mathrm{~nm}$ na água e $64000 \mathrm{~nm}$ no ar. Consequentemente a porosidade interna das rochas influencia na taxa de emanação do Radônio. 


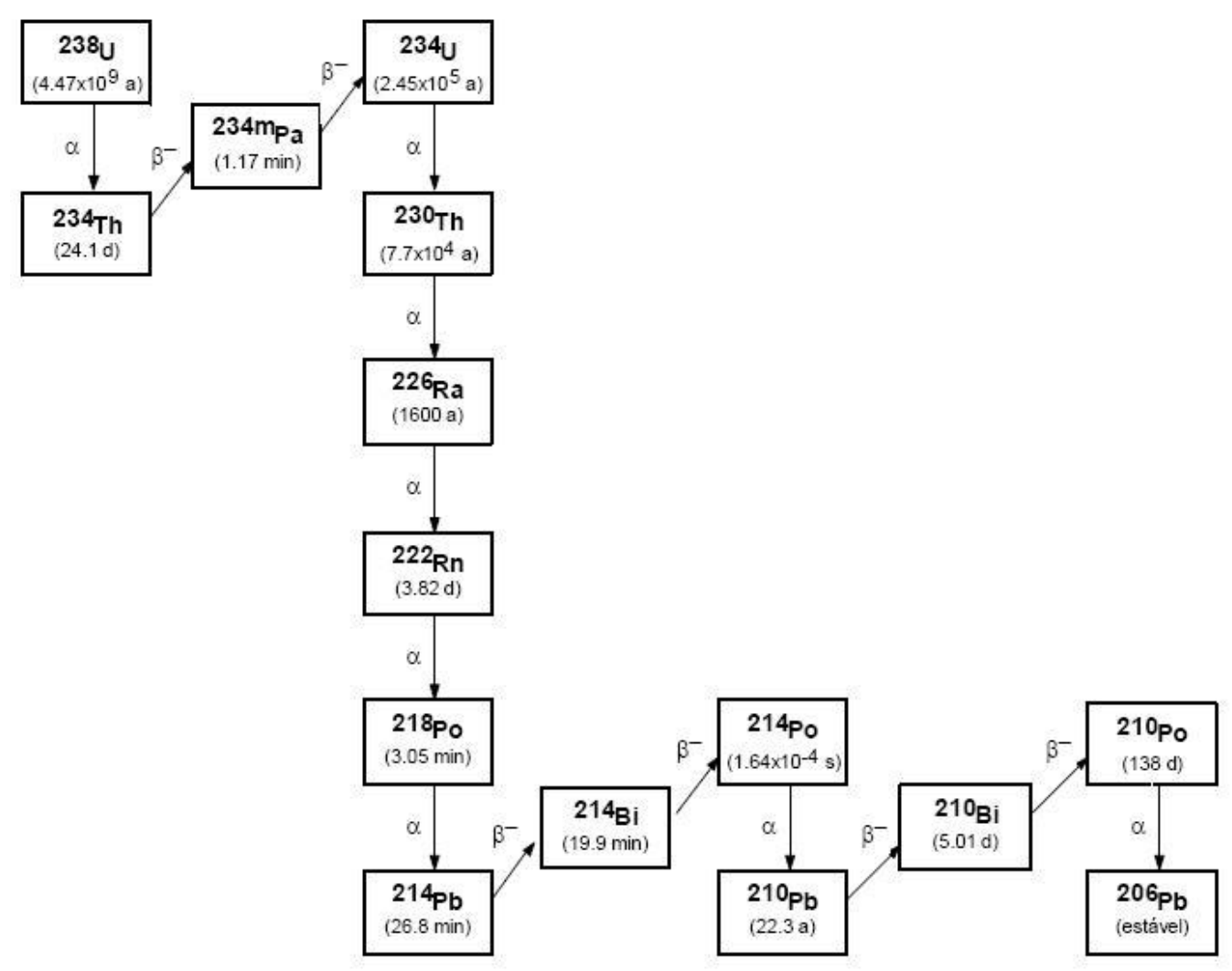

Figura 4.1 - Série de decaimento natural do U-238

(Fonte: IAEA, 1991).

A exalação do ${ }^{222} \mathrm{Rn}$ ou simplesmente radônio, não depende somente da atividade do ${ }^{226} \mathrm{Ra}$ e do coeficiente de emanação do solo, mas também depende das condições meteorológicas e do teor de umidade do solo (Kraner 1964). 


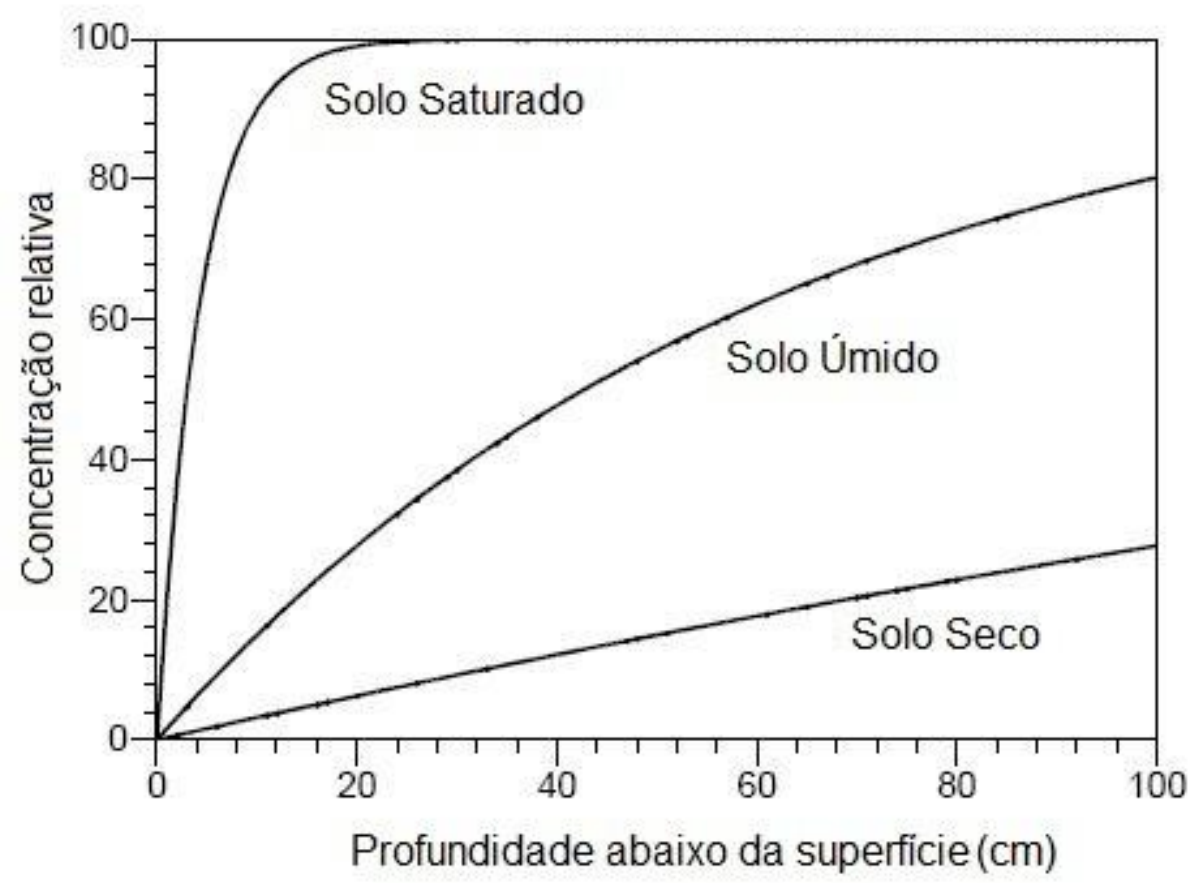

Figura 4.2 - Efeito da umidade do solo sobre a concentração de radônio (Fonte: Grasty \& Minty, 1995).

\subsection{Radônio na Atmosfera}

O ${ }^{222} \mathrm{Rn}$ que é produzido no solo por decaimento do ${ }^{226} \mathrm{Ra}$ difunde do solo para a atmosfera (Beck, 1974). Ele e os produtos de seu decaimento uma vez na atmosfera podem contribuir significativamente para medidas indesejadas de radiação gama (Burson et al, 1974). O Radônio exalado é transportado para cima por processos de difusão turbulenta, e pode ser levado para altitudes consideráreis. Os filhos do radônio, ${ }^{214} \mathrm{~Pb}(\mathrm{~T} 1 / 2=26,8 \mathrm{~min}) \mathrm{e}$ ${ }^{214} \mathrm{Bi}(\mathrm{T} 1 / 2=19,8 \mathrm{~min}$ ), são os dois principais emissores gamas (Gat et al, 1966). Esses radionuclídeos se ligam às partículas de poeiras na atmosfera, e sua precipitação é causada pela ação da chuva. Isso pode levar a um aumento de até $2.000 \%$ de concentrações de urânio no solo (Grasty \& Minty, 1995). Em 
função desse fenômeno, em aerolevantamentos é recomendado aguardar 3 horas após uma chuva para que o sistema esteja em equilíbrio (Grasty \& Minty, 1995).

Outra consideração importante com relação à radioatividade no ar e sua influência nos dados provenientes de aerolevantamentos é o fato dos radionuclídeos filhos do radônio ficarem trapeados na camada de inversão térmica ou também conhecida como camada limite atmosférica (Grasty, 2003). Como a altura desta camada varia ao longo do dia e entre os dias, os dados poderão sofrer influências.

Grasty \& Minty (1995) perceberam que as concentrações máximas de radônio são observadas nas horas da manhã e nas estações outuno-inverno.

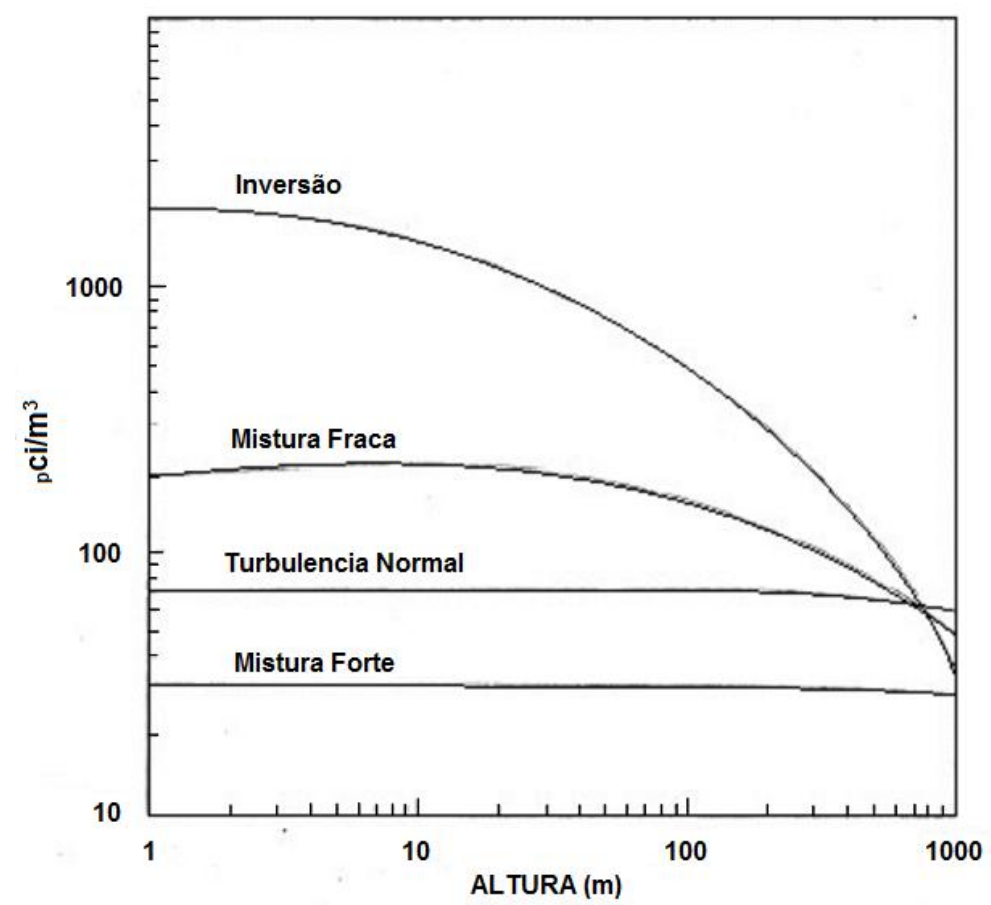

Figura 4.3 - Concentrações calculadas para ${ }^{214} \mathrm{~Pb}$ e ${ }^{214} \mathrm{Bi}$ na baixa atmosfera para uma fonte de um átomo de radônio exalado/ $\mathrm{cm}^{2} / \mathrm{s}$

(Fonte: Jacobi \& André, 1963). 
A figura acima apresenta o resultado do trabalho de Jacobi e André (1963), onde foram determinadas as concentrações para ${ }^{214} \mathrm{~Pb}$ e ${ }^{214} \mathrm{Bi}$ na baixa atmosfera para quatro diferentes processos de difusão: difusão turbulenta forte, difusão moderada, mistura fraca e inversão forte.

De acordo com as informações descritas, a concentração de radônio atmosférico dependerá então das: taxas de emanação do solo, taxas de difusão atmosférica, taxas de advecção (componente horizontal do vento) e taxas de decaimento radioativo.

\subsection{Outras Fontes Radioativas na Atmosfera}

Temos ainda outras fontes de radiação gama atmosférica:

- Elementos cosmogênicos que entram na atmosfera como consequência da poeira cósmica e micrometeoritos $\left({ }^{26} \mathrm{Al},{ }^{10} \mathrm{Be},{ }^{6} \mathrm{Ca}\right)$, bem como os formados na atmosfera por reações nucleares causadas por raios cósmicos $\left({ }^{7} \mathrm{Be},{ }^{14} \mathrm{Ca}\right.$, Trítio, ${ }^{32} \mathrm{~K}$, etc) (Kogan et al, 1969).

- As aeronaves e equipamentos contêm traços de material radioativo que podem contribuir para a radiação de fundo (Billings, 2006).

- Resíduos das radiações de explosões nucleares (Fallout). 


\section{REDUÇÃo DAS MEDIDAS DE TAXA DE CONTAGENS PARA CONCENTRAÇÃO DOS ELEMENTOS}

Medidas em taxa de contagens (cps) não dependem somente das concentrações dos radioelementos na superfície, mas também do equipamento usado e da altura nominal de voo (Krausz et al, 2003).

Nesse trabalho foram determinadas as concentrações em diferentes dias para uma mesma linha de $8 \mathrm{~km}$ de direção $\mathrm{E}-\mathrm{W}$, que será chamada nesse trabalho como linha de repetibilidade radiométrica. Situada próximo às cidades de Anagé e Caraíbas no estado da Bahia. A linha apresenta uma topografia relativamente plana e foi medida 88 vezes em 43 dias diferentes: 42 dias duas vezes ao dia e um dia quatro vezes. Esses dados são testes diários referentes ao projeto Aerogeofísico Barra da Estiva - Tremedal da Companhia Baiana de Pesquisa Mineral - CBPM. As medidas foram realizadas a uma altura média de 81 metros, com o espectrômetro transportado pela aeronave Piper Navajo Chieftain PA31-350 de prefixo PR-PRS da empresa Prospectors Aerolevantamentos e Sistemas LTDA. As medidas foram realizadas entre 17 de março e 31 de maio de 2008. 


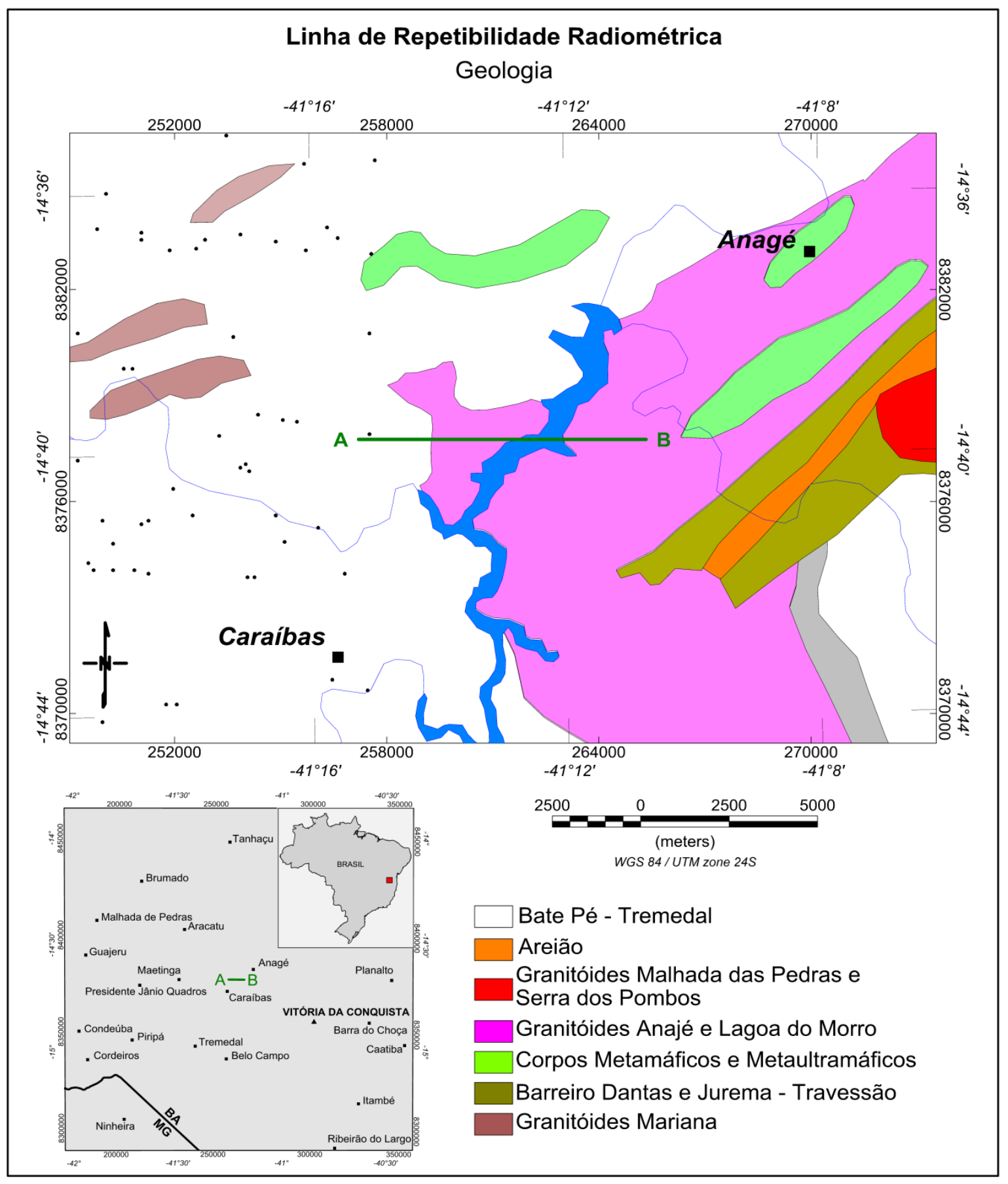

Figura 5.1 - Geologia e localização associada à linha de estudo (Linha A-B).

(Fonte: Carta Geológica do Brasil ao Milionésimo, CPRM)

Imediatamente antes ou após a realização dessas medidas, foram realizadas leituras há uma altura acima de 2.500 pés $(762 \mathrm{~m})$ em um trecho de $10 \mathrm{~km}$, conhecido como teste de radiação gama atmosférica. Os dados de 
radiação gama atmosférica apresentaram variações superiores às recomendadas pelos manuais IAEA-323 de 1991 ou IAEA-1363 de 2003, para uma aquisição de dados de boa qualidade. Justamente por esse motivo os dados desse local foram escolhidos para análise nesse trabalho.

O espectrômetro gama utilizado foi da marca Exploranium, modelo GR820, de 256 canais espectrais, onde o espectro de cada um dos cristais é analisado individualmente para determinação precisa dos fotopicos. Uma correção linear é aplicada a cada cristal, mantendo o espectro permanente alinhado. As radiações gama detectadas, são somadas e as leituras reduzidas a uma única saída de 256 canais espectrais. As leituras do gamaespectrômetros foram realizadas a cada segundo (contagens por segundo ou cps), representando medições com intervalos de amostragem de aproximadamente $80 \mathrm{~m}$. Cada sistema detector voltado para baixo (downward looking) é constituído por três conjuntos de cristais de iodeto de sódio ( $\mathrm{Nal}$ ), sendo dois de 1.024 polegadas cúbicas e um de 512 polegadas cúbicas. O Sistema detector voltado para cima (upward looking) é constituído por dois cristais de 256 polegadas cúbicas, totalizando 512 polegadas cúbicas. Esses voltados para cima monitoram as radiações decorrentes da influência do radônio na faixa energética do canal de urânio (1,66 a 1,86 MeV). 
Tabela 4.1 - Faixas energéticas do Gamaespectrômetro e os canais correspondentes ao equipamento utilizado no levantamento (Fonte: Relatório do Projeto Aerogeofísico Barra da Estiva-Tremedal, CBPM).

\begin{tabular}{|c|c|c|c|c|}
\hline Canal Radiométrico & \multicolumn{2}{|c|}{ Faixa de Energia (MeV) } & \multicolumn{2}{c|}{ Canais correspondentes } \\
\hline Contagem Total & 0,41 & 2,81 & 34 & 233 \\
\hline Potássio & 1,37 & 1,57 & 155 & 131 \\
\hline Urânio & 1,66 & 1,86 & 139 & 155 \\
\hline Tório & 2,41 & 2,81 & 202 & 233 \\
\hline Cósmico & 3,00 & $\infty$ & 25 & - \\
\hline
\end{tabular}

A altura da aeronave foi monitorada através dos altímetros de radar e dos barômetros de precisão incluídos no sistema aerogeofísico. O radar altímetro utilizado foi o Terra, modelo TRA-3000 com alcance de 2500 pés ( 760 metros). Os barômetros são transdutores de pressão que registram a altitude de voo em relação ao nível do mar. Todos os equipamentos altímetros apresentam precisão de 40 pés ( 12 metros).

A navegação foi efetuada por sistemas GPS de 12 canais, receptores MIDTECH RX-400P. A aeronave estava equipada com sistema de correção em tempo real (DGPS real time).

\subsection{Calibrações e Testes}

Para determinar as concentrações dos radioelementos em superfície a partir de medidas realizadas no espectrômetro gama aerotransportado, são necessários alguns importantes testes e calibrações. A grande maioria dos levantamentos para mapeamento geológico através de aeroespectrometria 
gama é realizada de acordo com os seguintes manuais: "A guide to the technical specifications for airborne gamma-ray surveys" da Organização Australiana de Levantamento Geológicos (AGSO - Australian Geological Survey Organisation) dos pesquisadores Grasty e Minty (1995), ou pelo "Guidelines for radioelement mapping using gamma ray spectrometry data (IAEA-1363)" da Agencia Internacional de Energia Atómica (IAEA International Atomic Energy Agency) de Krausz e participação de outros pesquisadores (2003); para este trabalho não foi diferente. As seções a seguir apresentam uma breve revisão teórica, bem como um relato dos testes e calibrações utilizados nesse trabalho para determinar as concentrações em superfície, a partir das medidas de taxa de contagem realizadas com 0 equipamento transportado pela aeronave. Neste processo enfatizou-se a correção das variações de radônio atmosférico, variação essa que está diretamente ligada às variações diárias nas medidas de raios gama em espectrômetros aerotransportados.

Importante ressaltar que como os dados são provenientes de um projeto aerogeofísico e obedecem às normas dos manuais descritos no parágrafo anterior, os dados possuem um controle de qualidade prévio, como teste em solo com amostras para verificação da resolução dos cristais dos detectores, bem como medidas em condições meteorológicas favoráveis.

\subsubsection{Correção do Tempo Morto}

Espectrômetros gama demandam de um tempo finito para processar cada pulso do detector. Enquanto um pulso esta sendo processado, outro pulso pode ser rejeitado. Consequentemente o tempo "vivo" (live time) de um 
espectrômetro é reduzido ao tempo necessário para processar todos os pulsos que atingem a analisador (Grasty \& Minty, 1995).

O equipamento utilizado informava o tempo "vivo" para cada leitura. A correção das contagens para cada segundo é dada por (Grasty \& Minty, 1995):

$$
N=\frac{n \times 1000}{l}
$$

Onde $l$ é o tempo "vivo" para cada segundo e $n$ as contagens gravadas por segundo.

\subsubsection{Radiação Cósmica de Fundo e Radiação da Aeronave}

Radiação cósmica consiste principalmente em partículas de alta energia provenientes do sol ou do espaço que interagem com a atmosfera da Terra e dão origem a uma radiação secundária de partículas e raios gama. Raios cósmicos aumentam com a altitude duplicando a cada 2000 metros, e apresentam pouca variação com latitude (Krausz et al, 2003).

As aeronaves e equipamentos contêm traços de material radioativo que podem contribuir para a radiação de fundo. No entanto, essa radiação é constante e pode ser determinada.

Para determinar os valores de radiação de fundo da aeronave e o coeficiente de radiação cósmica de fundo é realizado anualmente um teste sobre o mar, em diferentes altitudes e numa distância suficientemente longe da costa, onde a presença de produtos de decaimentos de radônio é mínima.

$\mathrm{Na}$ ausência de radônio e radiação terrestre, a taxa de contagem na janela de raios cósmicos está relacionada com as contagens devido à radiação 
cósmica em qualquer outra janela espectral, ou no canal individual pela função linear (IAEA,2003):

$N=a+b c$

Onde: $N=$ taxa de contagem em uma determinada janela;

$a=$ radiação de fundo da aeronave em determinada janela;

$b=$ coeficiente que relaciona a taxa de contagem em determinada janela com a taxa de contagem no canal cósmico;

$C=$ taxa de contagem no canal cósmico (Energia $>3,0 \mathrm{MeV})$.

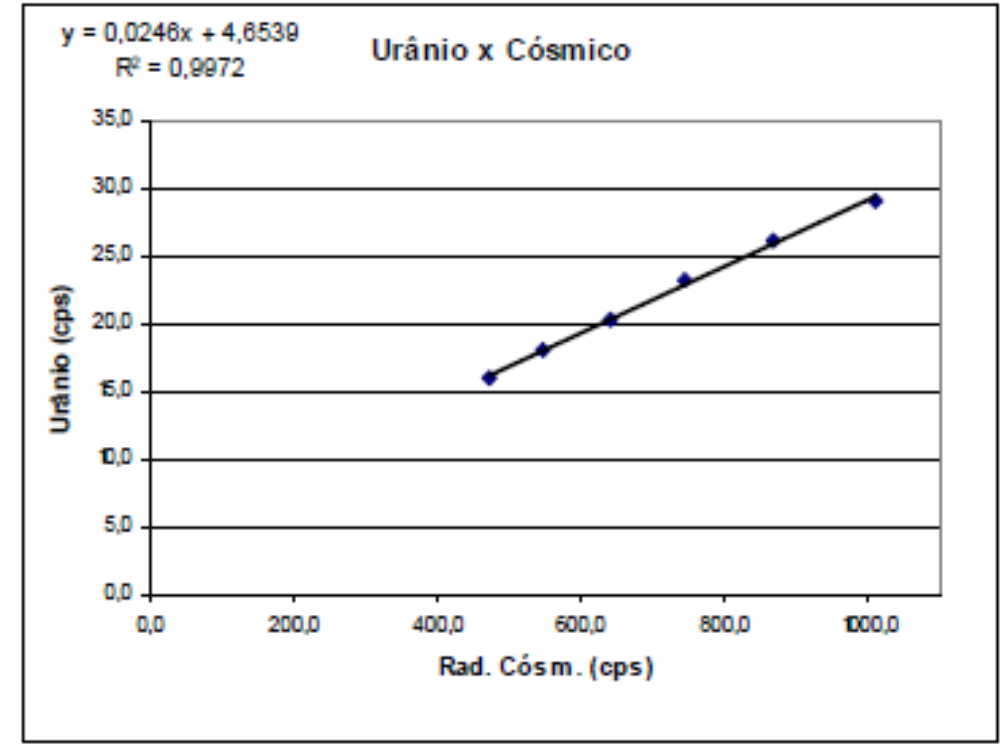

Figura 5.2 - Ajuste para determinação dos coeficientes de radiação cósmica e radiação de fundo para a janela do urânio.

(Fonte: Relatório do Projeto Aerogeofísico Barra da Estiva-Tremedal, CBPM).

A figura 5.2 apresenta o resultado do teste de determinação da radiação de fundo da aeronave e do coeficiente de radiação cósmica de fundo: 4,6539 
cps e 0,0246 respectivamente. Esses valores foram determinados em voo sobre o mar na altitudes de 4.500, 5.500, 6.500, 7.500, 8.500, 9.500, 10.500, 11.500 e 12.500 pés com duração de 15 minutos em cada altitude. O teste foi realizado no dia 05 de junho de 2007.

A tabela 5.1 a seguir, apresenta os valores utilizados para todas as janelas.

Tabela 5.1 - coeficientes de radiação cósmica e radiação de fundo (Fonte: Relatório do Projeto Aerogeofísico Barra da Estiva-Tremedal, CBPM).

\begin{tabular}{|l|l|}
\hline Canal Radiométrico & Valores \\
\hline \multirow{2}{*}{ Contagem Total } & $\mathrm{a}=152,8900 \mathrm{cps}$ \\
\cline { 2 - 2 } Potássio & $\mathrm{b}=0,5304$ \\
\hline \multirow{2}{*}{ Urânio } & $\mathrm{a}=23,275 \mathrm{cps}$ \\
\cline { 2 - 2 } & $\mathrm{b}=0,0261$ \\
\hline \multirow{2}{*}{ Tório } & $\mathrm{a}=4,6539 \mathrm{cps}$ \\
\cline { 2 - 2 } & $\mathrm{b}=0,0246$ \\
\hline \multirow{2}{*}{ Urânio Up (detector voltado para cima) } & $\mathrm{a}=2,2218 \mathrm{cps}$ \\
\cline { 2 - 2 } & $\mathrm{b}=0,0049$ \\
\cline { 2 - 2 } & $\mathrm{b}=0,0298$ \\
\hline
\end{tabular}




\subsubsection{Correção do Radônio Atmosférico}

A remoção da componente de fundo do radônio nas janelas do urânio, tório e potássio é uma parte essencial para conversão das taxas de contagens para concentração em superfície, pois infelizmente um dos produtos do decaimento do ${ }^{222} \mathrm{Rn}$ é o ${ }^{214} \mathrm{Bi}$, que é o radionuclídeo usado para medir o urânio presente na superfície (Figura 5.3).

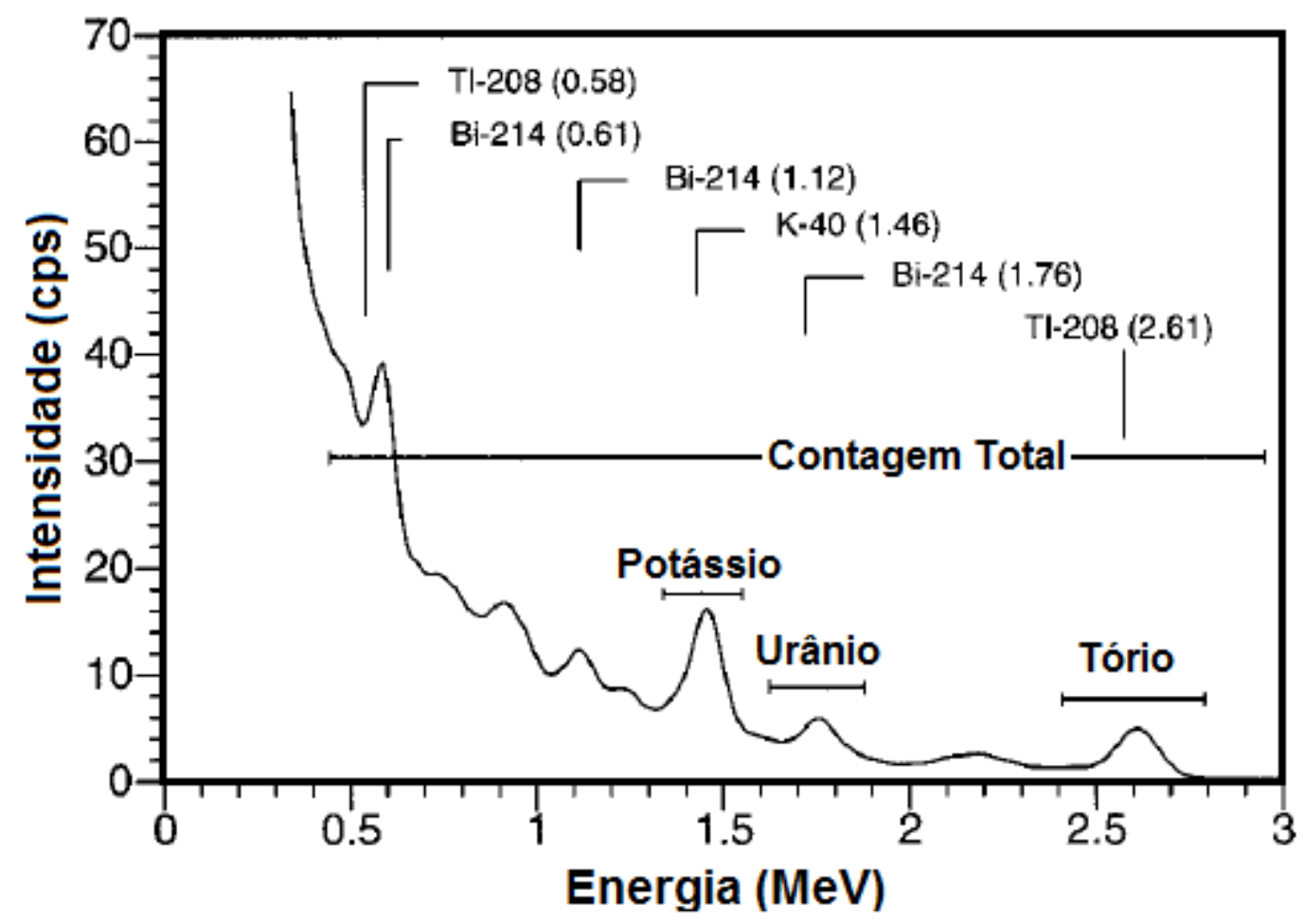

Figura 5.3 - Espectro de radiação gama indicando a faixa de energia e seus radionuclídeos

(Fonte: Minty et al, 1997).

Segundo Krausz et al (2003) há três métodos que podem ser usados para remover a radiação atmosférica de fundo do radônio: método da razão espectral, do espectro completo e com detectores voltados para cima. Nesse ultimo, os detectores fornecem ao espectrômetro uma sensibilidade direcional 
capaz de distinguir as fontes provenientes do radônio atmosférico das fontes terrestres de radiação, podendo ser inclusive utilizados em locais contaminados com ${ }^{137} \mathrm{Cs}$. O método de correção a partir da instalação de detectores voltados para cima é utilizado nos levantamentos brasileiros, sendo também o utilizado nesse trabalho.

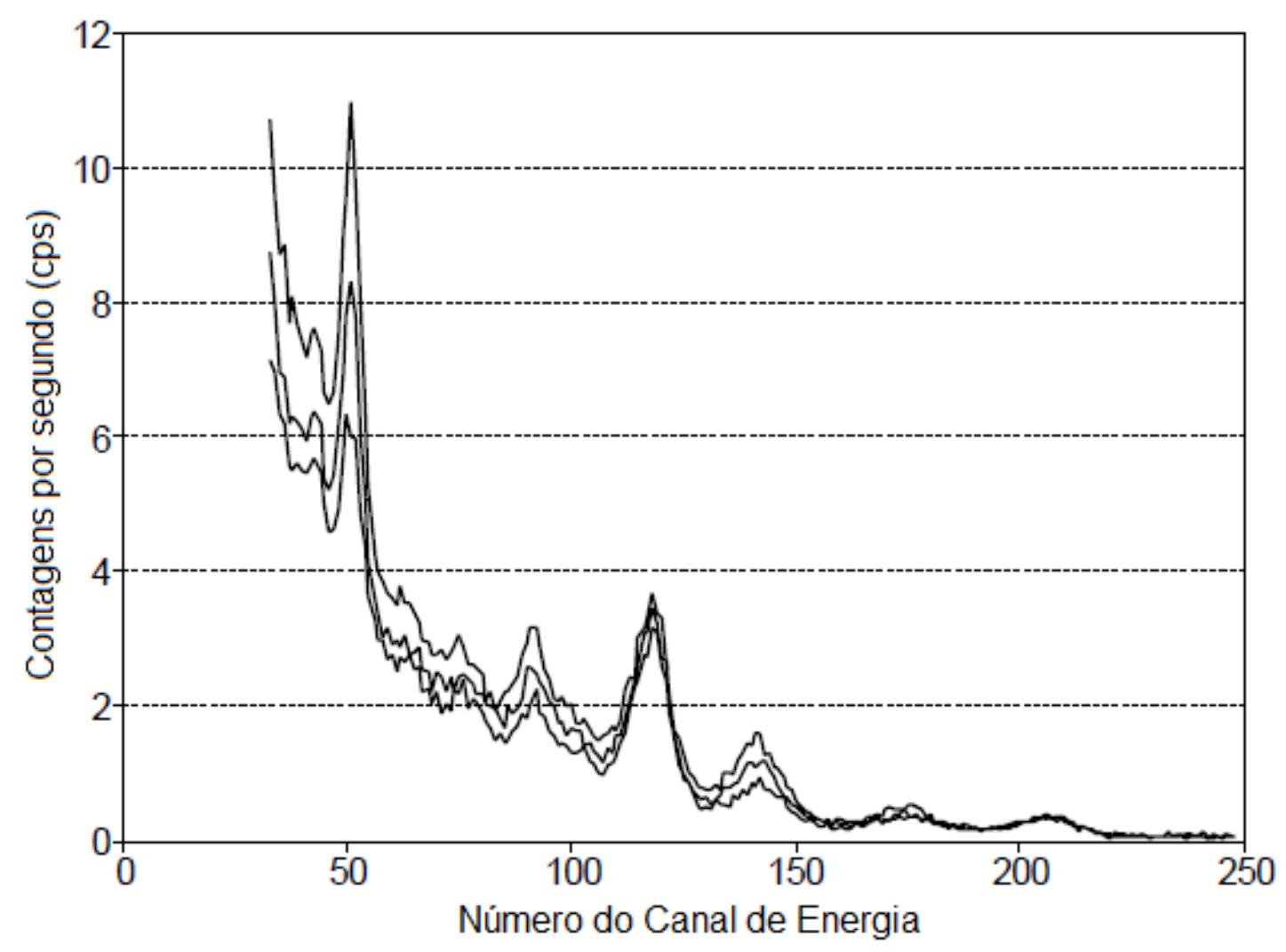

Figura 5.4 - Variações do espectro associadas à variação do radônio atmosférico

(Fonte: Grasty \& Minty, 1995). 


\subsubsection{Método com Detectores Voltados para Cima}

Utiliza-se um "pacote" adicional de cristal que é parcialmente blindado das radiações provenientes de fontes localizadas abaixo do sistema, discriminando então as radiações da atmosfera das radiações da superfície terrestre.

A contribuição do radônio e de seus filhos na janela do urânio nos detectores principais (detectores voltados para baixo) é dado por (IAEA, 1991):

$$
U_{r}=\frac{u-a_{1} U-a_{2} T+a_{2} b_{t}-b_{u}}{a_{u}-a_{1}-a_{2} a_{t}}
$$

Onde: $U_{r}=$ Radiação de fundo do radônio medido na janela do urânio dos detectores voltados para baixo (detectores principais);

$u=$ contagem medida na janela do urânio dos detectores voltados para cima;

$U=$ contagem medida na janela do urânio dos detectores voltados para baixo;

$T=$ contagem medida na janela do tório dos detectores voltados para baixo.

$a_{1}, a_{2}, a_{u}, a_{t}, b_{u}$ e $b_{t}$ são constantes derivadas de calibrações apropriadas.

O primeiro passo para calibrar os detectores voltados para cima (upward looking) é determinar uma relação entre as contagens na janela do urânio nesses detectores com as da janela do urânio nos detectores principais (downward looking). Nesse processo também são determinados às relações entre as contagens nas janelas dos detectores principais: urânio com as 
demais janelas. A relação é expressa por um conjunto de coeficientes obtidos a partir de dados de voos realizados sobre a água, ou a uma altura elevada, onde não existe qualquer influência de radiações provenientes do solo e rochas, sendo o primeiro o mais indicado (IAEA, 1991). A radiação de fundo da aeronave e a radiação cósmica de fundo deverão ser removidas para determinar os coeficientes.

Após a remoção da radiação de fundo da aeronave e a radiação cósmica de fundo, somente componentes relacionadas com o radônio atmosférico permaneceram nas janelas dos radioelementos. As alterações em todas as janelas, de tempos em tempos ou de um lugar para outro devido a variações nas concentrações de ${ }^{214} \mathrm{Bi}$ no ar; portanto janelas de $\mathrm{K}$, Th, contagem total e nas janelas do $\mathrm{U}$ (downward e upward) variam linearmente uma com a outra. No voo de calibração, as medidas de taxa de contagem para o tório são próximas de zero após a remoção da radiação de fundo da aeronave e a radiação cósmica de fundo, porque somente uma pequena porcentagem de raios gama de ${ }^{214} \mathrm{Bi}$ tem alta energia suficiente para serem detectadas na janela do tório (IAEA, 1991).

A relação entre as contagens na janela do $U$ nos detectores voltados para baixo referentes ao radônio atmosférico com as outras janelas obedecem as seguintes relações (IAEA,1991):

$$
\begin{aligned}
& u_{r}=a_{u} U_{r}+b_{u} \\
& K_{r}=a_{K} U_{r}+b_{K} \\
& T_{r}=a_{T} U_{r}+b_{T}
\end{aligned}
$$




$$
C T_{r}=a_{C T} U_{r}+b_{C T}
$$

Onde $u_{r}$ é a componente referente ao radônio na janela do urânio no detector voltado para cima e $U_{r}, K_{r}, T_{r}$ e $C T_{r}$ são as componentes referentes ao radônio nas outras janelas; urânio, tório, potássio e contagem total respectivamente. Os coeficientes $a$ e $b$ são as constantes de calibração. No caso de $b$, se a radiação de fundo da aeronave e a radiação cósmica de fundo foram devidamente removidas o seu valor deverá ser zero (IAEA, 1991).

Os dados dos testes diários, realizado a uma altura superior a 760 metros (aproximadamente 2500 pés) foram utilizados para determinar os coeficientes $a_{u}, a_{K}, a_{T}, a_{C T}, b_{u}, b_{K}, b_{T}$ e $b_{C T}$ para a correção do radônio atmosférico.

A figura 5.5 apresenta a localização dos testes de calibração referente ao radônio atmosférico (linhas pretas) e a localização da linha de repetibilidade radiométrica (amarela). 


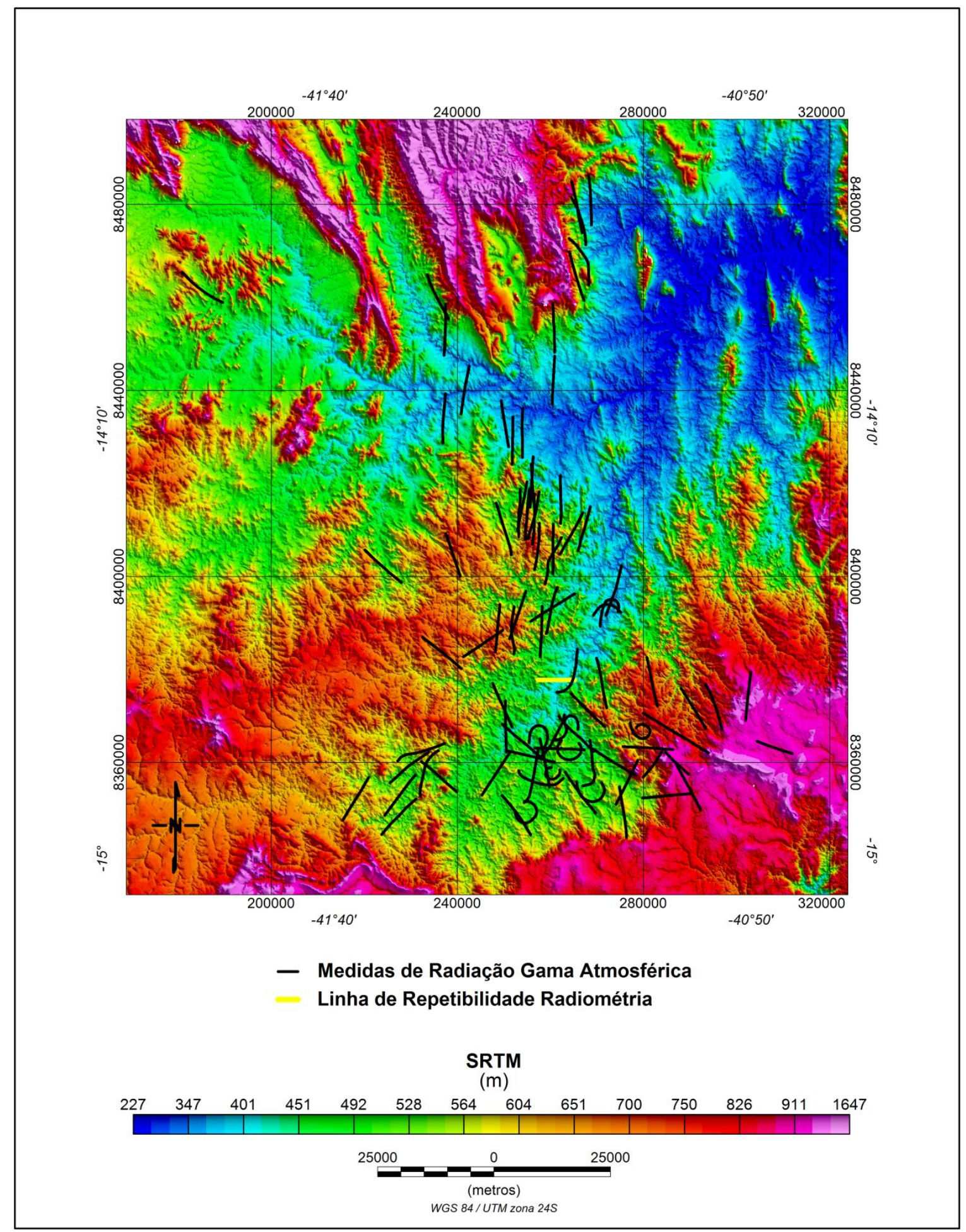

Figura 5.5 - Disposição espacial da linha de repetibilidade radiométrica e as linhas de radiação gama atmosférica.

As figuras 5.6, 5.7, 5.8 e 5.9 apresentam os resultados dos testes de calibração dos detectores voltados para cima. Os gráficos mostram a relação 
entre a janela do urânio com as demais janelas dos detectores voltados para baixo e a relação entre os detectores nas janelas do urânio (upward e downward).

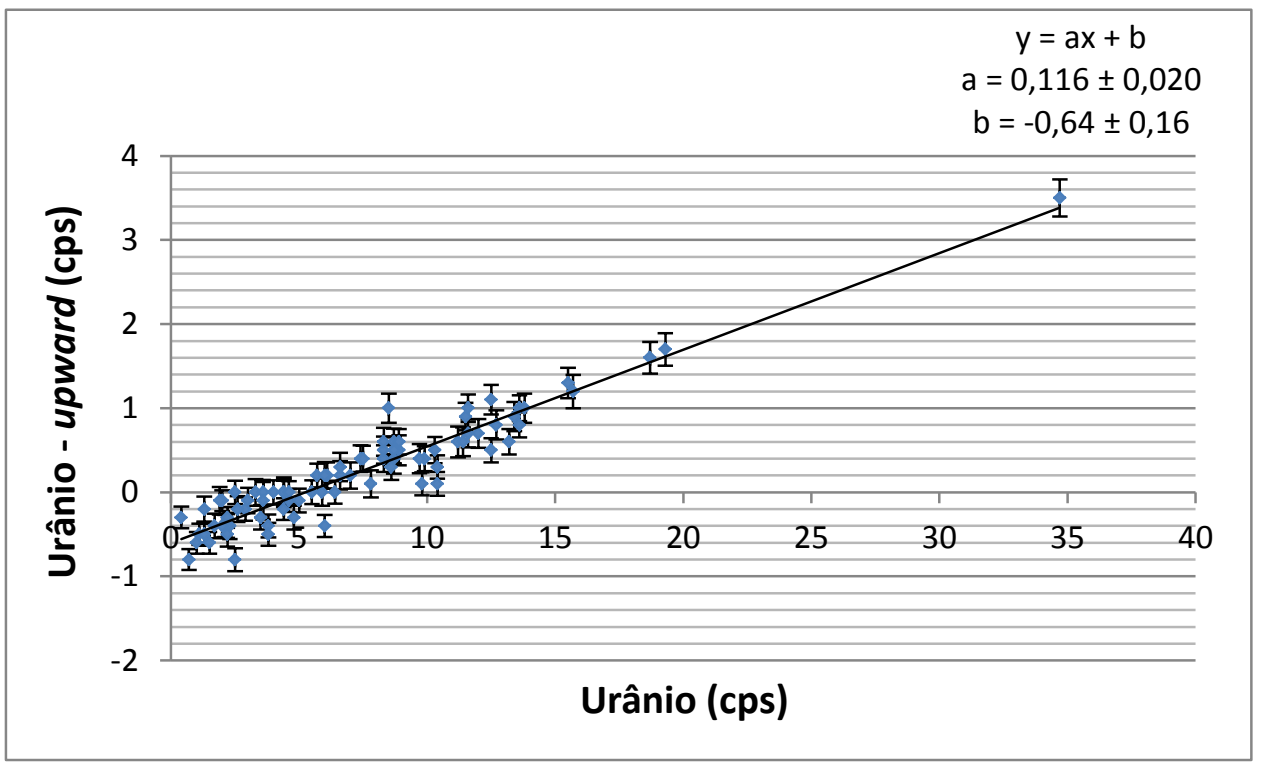

Figura 5.6 - Relação entre os detectores nas janelas do urânio.

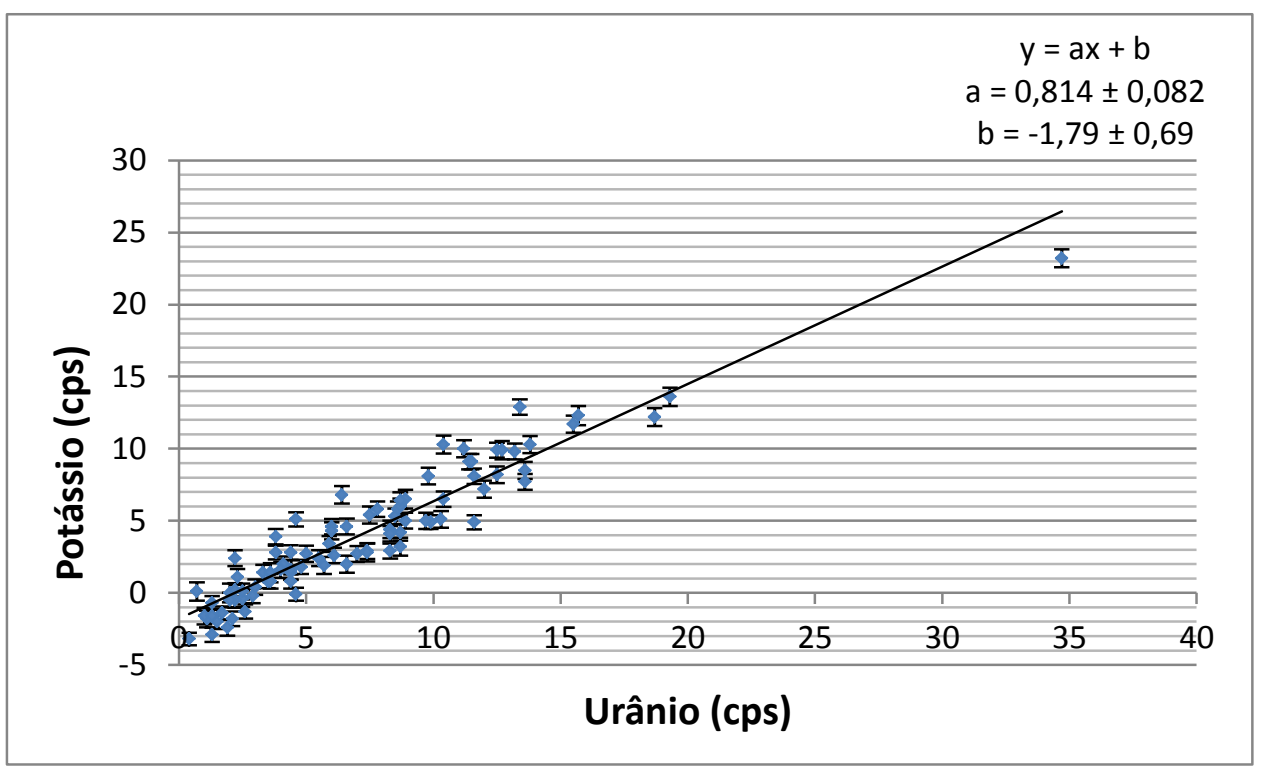

Figura 5.7 - Relação entre a janela do urânio e a do potássio. 


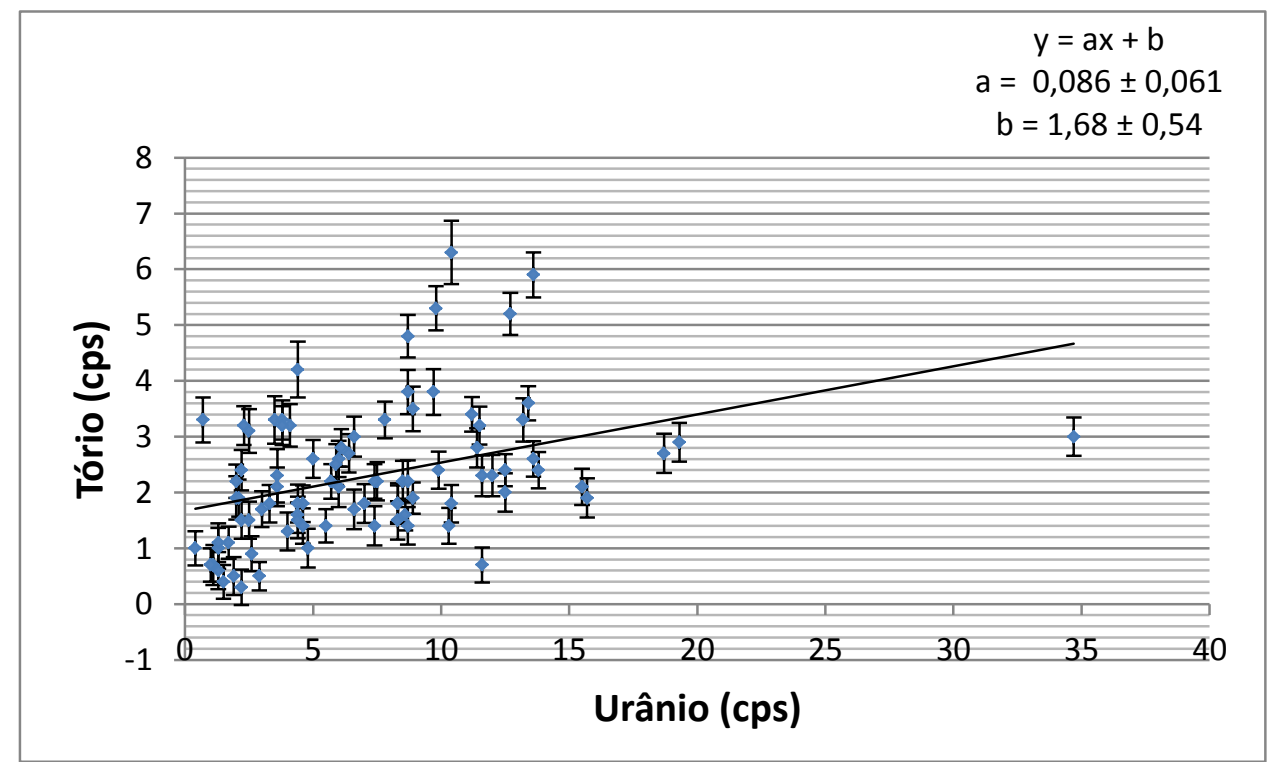

Figura 5.8 - Relação entre a janela do urânio e a do tório.

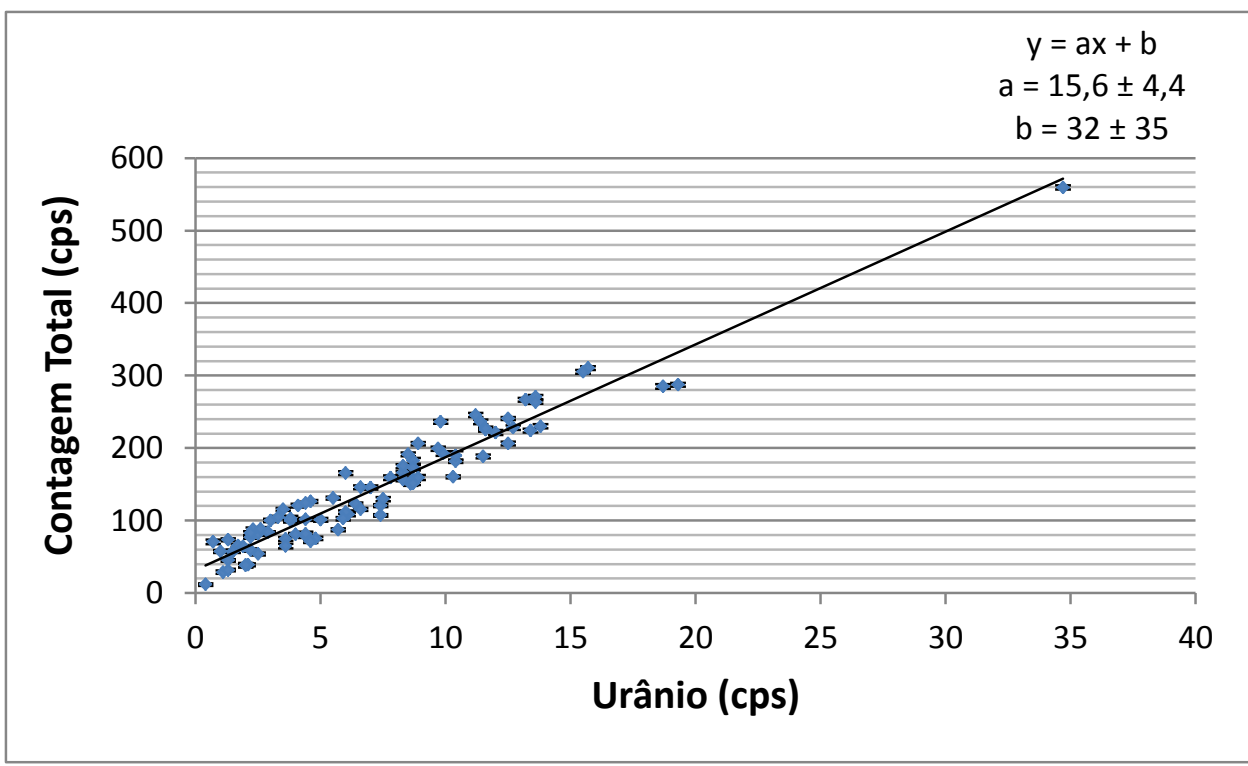

Figura 5.9 - Relação entre a janela do urânio e a de contagem total.

A tabela 5.2 mostra os valores dos coeficientes $a$ e $b$ obtidos no teste de calibração dos detectores voltados para cima. 
Tabela 5.2 - coeficientes de calibração dos detectores voltados para cima.

\begin{tabular}{|l|l|}
\hline Janela & Coeficiente \\
\hline Urânio upward & $\begin{array}{l}a_{u}=0,116 \pm 0,020 \\
b_{u}=-0,64 \pm 0,16\end{array}$ \\
\hline Potássio & $\begin{array}{l}a_{K}=0,814 \pm 0,082 \\
b_{K}=-1,79 \pm 0,69\end{array}$ \\
\hline Tório & $a_{T}=0,086 \pm 0,061$ \\
& $b_{T}=1,68 \pm 0,54$ \\
\hline Contagem Total & $a_{C T}=15,6 \pm 4,4$ \\
& $b_{C T}=32 \pm 35$ \\
\hline
\end{tabular}

Considerando que os dados foram devidamente corrigidos dos efeitos da radiação cósmica de fundo e da radiação de fundo da aeronave e após análise dos valores significativos dos coeficientes $b_{u}, b_{K}, b_{T}$ e $b_{C T}$, esses foram zerados. Da equação 5.3 resulta então:

$$
U_{r}=\frac{u-a_{1} U-a_{2} T}{a_{u}-a_{1}-a_{2} a_{t}}
$$

e das equações $5.4,5.5,5.6$ e 5.7 :

$$
\begin{aligned}
& u_{r}=a_{u} U_{r} \\
& K_{r}=a_{K} U_{r} \\
& T_{r}=a_{T} U_{r} \\
& C T_{r}=a_{C T} U_{r}
\end{aligned}
$$


O próximo estágio da calibração foi determinar a relação entre as taxas de contagens dos detectores voltados para cima das taxas dos detectores voltados para baixo, referentes à radiação originaria do solo e rochas, essa relação é dada pelos coeficientes $a_{1}$ e $a_{2}$. Esse processo não precisa de teste de calibração e foi determinado utilizando todos dos 88 testes de repetibilidade radiométrica corrigidos da radiação cósmica de fundo, radiação de fundo e radônio atmosférico.

A componente da taxa de contagem no detector voltado para cima provenientes da superfície, $u_{g}$, dependerá das concentrações de urânio e tório da superfície. Dessa forma é possível relacionar $u_{g}$ com as medidas de taxa de contagem das janelas do urânio $\left(U_{g}\right)$ e tório $\left(T_{g}\right)$ dos detectores voltados para baixo. Essa relação é dada pela seguinte equação linear (IAEA, 1991):

$$
u_{g}=a_{1} U_{g}+a_{2} T_{g}
$$

Onde $u_{g}, U_{g}$ e $T_{g}$ são as contribuições nas janelas provenientes de fontes nos solo e rochas.

Os dois coeficientes podem ser determinados resolvendo simultaneamente as seguintes equações:

$$
\begin{aligned}
& a_{1} \sum\left(U_{g}\right)^{2}+a_{2} \sum U_{g} T_{g}=\sum u_{g} U_{g} \\
& a_{1} \sum U_{g} T_{g}+a_{2} \sum\left(T_{g}\right)^{2}=\sum u_{g} T_{g}
\end{aligned}
$$

No entanto esse método envolve subtração de médias de seções de 10 segundos adjacentes para remover os efeitos da radiação cósmica, radiação 
de fundo da aeronave e radônio atmosférico. Esse procedimento pode apresentar dois sérios problemas (Grasty \& Hovgaard, 1996):

- Duas constantes de calibração podem ser difíceis de ser calculadas. Levantamentos realizados pelo serviço geológico do Canadá mostram que esses valores podem variar em um fator de 2. Acredita-se que isso ocorra por conta do alto grau de correlação entre a janela do urânio e a janela do tório. Essa correlação é devido à resposta no detector, que resulta em raios gama da janela do tório disperso na janela do urânio, bem como a correlação de urânio e tório no solo.

- Variações de radioatividade provenientes da superfície poderão ser perdidas pela subtração das medias adjacentes.

Grasty \& Hovgaard (1996) mostraram um simples procedimento para calcular a contribuição da radiação proveniente da superfície nos detectores voltados para cima: utilizando apenas a janela do urânio ou apenas a janela do tório dos detectores voltados para baixo. Ao invés de subtrair médias adjacentes para remover a radiação cósmica, radiação de fundo e radônio atmosférico o procedimento envolve a subtração de médias ao longo de cada linha para encontrar diferenças sucessivas. A janela de contagem total é utilizada para determinar se a radioatividade proveniente da superfície está aumentando ou diminuindo. Se a contagem total indica que a radioatividade está diminuindo, o sinal de ambos os detectores (voltados para cima e para baixo) são revertidas.

Esse procedimento assume que $a_{2}$ é nulo ou que $a_{1}$ é nulo. Assumindo $a_{2}=0$, então $a_{1}$ (Grasty e Hovgaard ,1996): 


$$
a_{1}=\frac{\sum u_{n}-u_{n+m}}{\sum U_{n}-U_{n+m}}
$$

Onde: $u_{n}=$ é a leitura na janela do urânio no detector voltado para cima;

$u_{n+m}=$ é a leitura da amostra seguinte na janela do urânio no detector voltado para cima;

$U_{n}=$ é a leitura na janela do urânio no detector voltado para baixo.

$U_{n+m}=$ é a leitura da amostra seguinte na janela do urânio no detector voltado para baixo.

Consequentemente da equação 5.8 resulta então que a radiação referente ao radônio atmosférico na janela do urânio assumindo $a_{2}=0$, é dada por:

$$
U_{r}=\frac{u-a_{1} U-b_{u}}{a_{u}-a_{1}}
$$

Por outro lado, assumindo $a_{1}=0$, temos:

$$
a_{2}=\frac{\sum u_{n}-u_{n+m}}{\sum T_{n}-T_{n+m}}
$$

Onde: $T_{n}=$ é a leitura na janela do tório no detector voltado para baixo.

$T_{n+m}=$ é a leitura da amostra seguinte na janela do tório no detector voltado para baixo.

Logo $U_{r}$ assumindo $a_{1}=0$ :

$$
U_{r}=\frac{u-a_{2} T+a_{2} b_{t}-b_{u}}{a_{u}-a_{2} a_{t}}
$$


O erro associado ao valor de $a_{1}$ ou $a_{2}$ pode ser calculado nas somas das diferenças das leituras. Por exemplo, o erro nas diferenças das leituras do detector voltado para cima $\sigma(u)$ é dado por (Grasty e Hovgaard ,1996):

$$
\sigma^{2}(u)=\sum u_{n}-u_{n+m}
$$

Os valores de $a_{1}$ e $a_{2}$ determinados para as linhas de repetibilidade radiométrica foram:

Tabela 5.3 - Coeficientes $\boldsymbol{a}_{1}$ e $\boldsymbol{a}_{2}$ determinados.

\begin{tabular}{|l|l|}
\hline $\boldsymbol{a}_{1}$ & $0,0465 \pm 0,0015$ \\
\hline $\boldsymbol{a}_{2}$ & $0,0211 \pm 0,0010$ \\
\hline
\end{tabular}

\subsubsection{Calibração com Blocos Radioativos}

Cada janela espectral que é usada para determinar um radioelemento, irá também conter algum efeito dos outros dois radioelementos (espalhamento Compton). A correção dessa sobreposição espectral deve ser realizada no processo de determinação das concentrações.

Umas das formas para determinar os coeficientes de sobreposição ou coeficientes de espalhamento Compton para um determinado espectrômetro é utilizando blocos de concreto contendo concentrações conhecidas de urânio, tório e potássio (IAEA, 1991).

Realizado no aeroporto de Jacarepaguá-RJ em 04/06/2007, com o auxílio de 4 (quatro) tanques de concreto com respostas radiométricas para os elementos ${ }^{40} \mathrm{~K},{ }^{238} \mathrm{U},{ }^{232} \mathrm{Th}$ e dimensões de $1,0 \times 1,0 \times 0,3$ metros. A tabela 5.4 apresenta as concentrações dos tanques de calibração utilizados. 
Tabela 5.4 - concentrações dos tanques de calibração

(Fonte: Relatório do Projeto Aerogeofísico Barra da Estiva-Tremedal, CBPM).

\begin{tabular}{|l|l|l|l|}
\hline Tanque de calibração & $\mathbf{K}(\%)$ & eU (ppm) & eTh (ppm) \\
\hline 1 - Background & $1,41 \pm 0,01$ & $0,97 \pm 0,03$ & $2,26 \pm 0,10$ \\
\hline 2 - Potássio & $8,71 \pm 0,09$ & $0,32 \pm 0,02$ & $0,74 \pm 0,10$ \\
\hline 3 - Urânio & $1,34 \pm 0,02$ & $59,9 \pm 1,00$ & $3,40 \pm 0,14$ \\
\hline 4 - Tório & $1,34 \pm 0,02$ & $2,96 \pm 0,06$ & $136,0 \pm 2,10$ \\
\hline
\end{tabular}

A aeronave é estacionada sobre os tanques de calibração que são sequencialmente posicionados em cada caixa de cristais, permanecendo 10 minutos em cada tanque para acumulação de dados.

A notação adotada foi $\alpha, \beta$ e $\gamma$ para as razões de contagens detectadas nas janelas de menor energia por um de maior energia e $a, b$ e $g$ para as razões de contagens detectadas numa janela de maior energia por um de menor energia. O coeficiente " $\alpha$ " é referente à sobreposição do tório na janela do urânio, o coeficiente " $a$ " é a sobreposição reversa: urânio na janela do tório. O coeficiente " $\beta$ " diz respeito à sobreposição do tório na janela do potássio, " $b$ " a sobreposição reversa: potássio na janela do tório. Por ultimo, os coeficientes " $\gamma$ " e " $g$ ", são referentes à sobreposição do urânio na janela do potássio e do potássio na janela do urânio respectivamente.

As medidas de contagens nas janelas do potássio, urânio e tório: $n_{K}, n_{U}$ e $n_{T h}$ são linearmente relacionadas com as concentrações de potássio, urânio e tório dos tanques de calibração, $C_{K}, C_{U}$ e $C_{T h}$.

$$
n_{K}=S_{K, K} C_{K}+S_{K, U} C_{U}+S_{K, T h} C_{T h}+B_{K}
$$




$$
\begin{aligned}
& n_{U}=S_{U, K} C_{K}+S_{U, U} C_{U}+S_{U, T h} C_{T h}+B_{U} \\
& n_{T h}=S_{T h, K} C_{K}+S_{T h, U} C_{U}+S_{T h, T h} C_{T h}+B_{T h}
\end{aligned}
$$

Onde $B_{K}, B_{U}$ e $B_{T h}$ são as contagens de fundo originário: da superfície próxima do tanque, da radioatividade da aeronave e do equipamento, contribuições da radiação de fundo e radioatividade do ar. Os nove fatores "S" são referentes às contagens nas três janelas para cada um dos três radioelementos (sensibilidade). De acordo com Grasty e Minty (1995) os coeficientes de espalhamento Compton são dados por:

$$
\begin{aligned}
& \alpha=\frac{S_{U, T h}}{S_{T h, T h}} \\
& \beta=\frac{S_{K, T h}}{S_{T h, T h}} \\
& \gamma=\frac{S_{K, U}}{S_{U, U}} \\
& a=\frac{S_{T h, U}}{S_{U, U}} \\
& b=\frac{S_{T h, K}}{S_{K, K}} \\
& \alpha=\frac{s_{U, K}}{S_{K, K}}
\end{aligned}
$$

As equações $5.21,5.22$ e 5.23 têm quatro incógnitas. Para determiná-las é necessário medidas em quatro tanques de calibração.

$\mathrm{Na}$ pratica, os quatros conjuntos de equações com quatro incógnitas, podem ser reduzidos a um conjunto de três equações com três incógnitas, subtraindo as contagens e concentrações do tanque de background a partir 
daquelas dos tanques de urânio, tório e potássio (Grasty \& Minty, 1995). As radiações de fundo, $B_{K}, B_{U}$ e $B_{T h}$ são removidas no cálculo. Em notação matricial, a matriz de contagens $\mathbf{N}_{3 \times 3}$, é então relacionada com a matriz concentração $\mathbf{C}_{3 \times 3}$, e com a desconhecida matriz sensibilidade $\mathbf{S}_{3 \times 3}$ pela seguinte equação:

$\left|\begin{array}{ccc}n_{K, K} & n_{K, U} & n_{K, T h} \\ n_{U, K} & n_{U, U} & n_{U, T h} \\ n_{T h, K} & n_{T h, U} & n_{T h, T h}\end{array}\right|=\left|\begin{array}{ccc}S_{K, K} & S_{K, U} & S_{K, T h} \\ S_{U, K} & S_{U, U} & S_{U, T h} \\ S_{T h, K} & S_{T h, U} & S_{T h, T h}\end{array}\right| \times\left|\begin{array}{ccc}C_{K, K} & C_{K, U} & C_{K, T h} \\ C_{U, K} & C_{U, U} & C_{U, T h} \\ C_{T h, K} & C_{T h, U} & C_{T h, T h}\end{array}\right|$

Onde $n_{i, j}$ são as contagens e $c_{i, j}$ são as concentrações após a remoção dos valores do tanque Background. Assim sendo, temos:

$\mathbf{N}=\mathbf{S C}$

A partir do qual a matriz sensibilidade contendo os noves valores $S_{i, j}$ pode ser escrita como:

$\mathrm{S}=\mathrm{NC}^{-1}$

Para determinar a matriz sensibilidade e consequentemente os coeficientes de espalhamento Compton, foi utilizado o programa PADWIN e como entrada os dados acumulados em 10 minutos para cada tanque em cada pacote de cristal. Foram determinados valores para cada pacote detectores de 1.024 polegadas cúbicas, para o pacote de 512 polegadas cúbicas e para todos os pacotes posicionados para baixo, ou seja, para todas as 2.560 polegadas cúbicas de cristais "voltados para baixo" (Downward looking). A tabela 5.5 apresenta os resultados para todo o sistema gamaespetrométrico.

Tabela 5.5 - Valores dos coeficientes de espalhamento Compton (Fonte: Relatório do Projeto Aerogeofísico Barra da Estiva-Tremedal, CBPM). 


\begin{tabular}{|c|l|}
\hline Coeficientes & Valores \\
\hline$\alpha$ & $0,2596 \pm 0,0029$ \\
\hline$\beta$ & $0,4021 \pm 0,0066$ \\
\hline$\gamma$ & $0,7539 \pm 0,0096$ \\
\hline$a$ & $0,0622 \pm 0,0047$ \\
\hline$b$ & $0,0117 \pm 0,0028$ \\
\hline$g$ & $0,0090 \pm 0,0020$ \\
\hline
\end{tabular}

Importante ressaltar que de acordo com os trabalhos de Grasty e Minty (1995), os valores determinados para os coeficientes de espalhamento Compton indicam um bom sistema gamaespectrométrico.

A correção do espalhamento Compton nos dados das linhas de repetibilidade radiométrica foi realizada de acordo com (IAEA, 1991):

$$
\begin{aligned}
& n_{K, K}=\frac{n_{T h}\left(\alpha_{e} \gamma_{e}-\beta_{e}\right)+n_{U}\left(a \beta_{e}-\gamma_{e}\right)+n_{K}\left(1-a \alpha_{e}\right)}{A} \\
& n_{U, U}=\frac{n_{T h}\left(g \beta_{e}-\alpha_{e}\right)+n_{U}\left(1-b \beta_{e}\right)+n_{K}\left(b \alpha_{e}-g\right)}{A} \\
& n_{T h, T h}=\frac{n_{T h}\left(1-g \gamma_{e}\right)+n_{U}\left(b \gamma_{e}-a\right)+n_{K}(a g-b)}{A} \\
& A=1-g \gamma_{e}-a\left(\alpha_{e}-g \beta_{e}\right)-b\left(\beta_{e}-\alpha_{e} \gamma_{e}\right) \\
& \alpha_{e}=\alpha+0,00049 * h \\
& \beta_{e}=\beta+0,00065 * h \\
& \gamma_{e}=\gamma+0,00069 * h
\end{aligned}
$$


Onde: $n_{K, K}, n_{U, U}$ e $n_{T h, T h}$ são as taxas de contagens de cada elemento radioativo corrigidas do espalhamento Compton.

$n_{T h}, n_{U}$ e $n_{K}$ são as taxas de contagens de cada elemento radioativo corrigidos de radiação de fundo do equipamento, radiação cósmica de fundo e radônio atmosférico.

$\alpha_{e}, \beta_{e}$ e $\gamma_{e}$ são os coeficientes de espalhamento Compton determinados para altura $h$.

\subsubsection{Correção das Variações de Altura}

A correção altimétrica tem como objetivo referenciar os valores radiométricos a uma altura nominal de aquisição, nesse caso 100 metros. Ao realizar esse procedimento eliminam-se falsas anomalias presentes por conta de elevações topográficas.

As taxas de contagens variam exponencialmente com a altura, ao menos na faixa de altura em que as aeronaves se deslocam nos levantamentos aéreos. Uma estimativa da taxa de contagem nominal é dada por (IAEA, 1991):

$$
n=n_{0} e^{-\mu(H-h)}
$$

Onde: $\mu=$ coeficiente de atenuação atmosférica em determinada janela (por metros);

$$
\begin{aligned}
& n_{0}=\text { taxas de contagens observadas para a altura } h ; \\
& n=\text { taxas de contagens corrigidas para a altura nominal do levantamento }
\end{aligned}
$$
$(H)$. 
A expressão acima é válida para regiões com topografias suaves, onde a faixa de altura da aeronave varia entre 50 e 250 metros. A altura $h$ utilizada na equação 5.40 está sujeita a variações por conta da influência da temperatura e pressão no radar altímetro, uma vez que ambos influenciam na pressão do ar. Dessa forma, é necessário determinar a altura $h$, numa situação de condições normais de temperatura e pressão (CNTP): 273,15 K e 101,325 kPa. A altura em CNTP pressão e dado por (IAEA-323, 1991):

$$
h_{C N T P}=\frac{273,15 \times P \times h_{o b s}}{(T+273,15) \times(101,325)}
$$

Onde: $h_{o b s}=$ altura observada em metros;

$$
\begin{aligned}
& h_{C N T P}=\text { altura corrigida das variações de temperatura e pressão; } \\
& T=\text { temperatura do } \operatorname{ar}\left({ }^{\circ} \mathrm{C}\right) \\
& P=\text { Pressão barométrica }(\mathrm{kPa}) .
\end{aligned}
$$

A pressão barométrica pode ser determinada a partir das medidas de altitude barométrica de acordo com a seguinte expressão (Grasty \& Minty, 1995):

$$
P=1013 e^{\left(\frac{-A l t}{8581}\right)}
$$

Onde Alt é a altitude barométrica em metros. 


\subsubsection{Determinação dos Coeficientes de Atenuação Atmosférica}

Para realizar as correções de altimetria nos dados de espectrometria gama aerotransportada, é necessário determinar os coeficientes de atenuação atmosférica do equipamento para cada janela (urânio, tório, potássio e contagem total). Foram determinados a partir de um voo de calibração realizado sobre a linha de calibração dinâmica, que está localizada no município de Maricá estado do Rio de Janeiro, e foi definida pelo Serviço Geológico do Brasil (CPRM) e pelo Conselho Nacional de Energia Nuclear (CNEN). Para tal, foram realizadas as leituras em diferentes alturas: 200, 300, 400, 500, 600, 700 e 800 pés sobre a pista no dia 06 de junho de 2007.

A atenuação das radiações gama em relação ao afastamento da fonte pode ser expressa matematicamente pela equação (IAEA, 1991):

$$
n_{h}=n_{0} e^{-\mu h}
$$

Onde: $n_{h}=$ radiação a distancia $h$ da fonte;

$$
n_{0}=\text { radiação na superfície do terreno }(h=0)
$$

$\mu=$ coeficiente de atenuação atmosférica.

Da equação (5.43), aplicando logaritmo natural em ambos os lados da igualdade temos:

$$
\operatorname{Ln}\left(n_{h}\right)=-\mu h+\operatorname{Ln}\left(n_{0}\right)
$$

Que resulta na equação da reta de coeficiente angular $-\mu$.

A figura 5.10 apresenta o gráfico no qual foi determinado o coeficiente de atenuação atmosférica para a janela do urânio. As medidas das taxas de 
contagens estão corrigidas de: tempo morto, das radiações de fundo do equipamento, das radiações cósmicas de fundo, do radônio atmosférico bem como do efeito do espalhamento Compton.

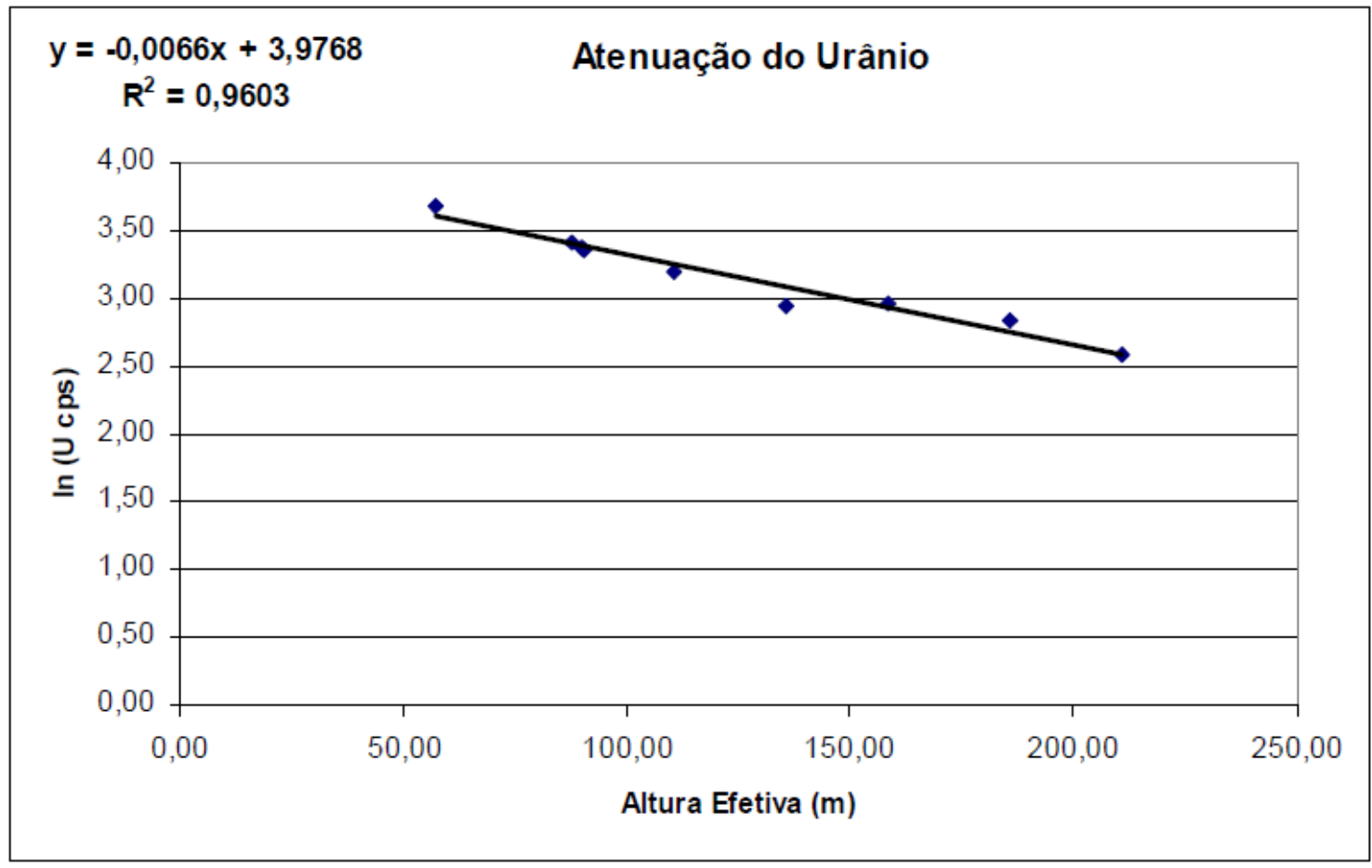

Figura 5.10 - Ajuste para determinação do coeficiente de atenuação atmosférica

(Fonte: Relatório do Projeto Aerogeofísico Barra da Estiva-Tremedal, CBPM).

A tabela 5.6 apresenta os valores utilizados para correção altimétrica no processo de determinação das concentrações dos radioelementos desse trabalho. 
Tabela 5.6 - coeficiente de atenuação atmosférica

(Fonte: Relatório do Projeto Aerogeofísico Barra da Estiva-Tremedal, CBPM).

\begin{tabular}{|l|l|}
\hline Canal Radiométrico & Coeficiente $\boldsymbol{\mu}\left(\mathbf{m}^{-1}\right)$ \\
\hline Contagem Total & $-0,0068$ \\
\hline Potássio & $-0,0087$ \\
\hline Urânio & $-0,0066$ \\
\hline Tório & $-0,0071$ \\
\hline
\end{tabular}

\subsubsection{Conversão para concentração}

A partir das taxas de contagens corrigidas de: tempo "morto", radiação de fundo do equipamento, radiação cósmica, radônio atmosférico, espalhamento Compton e correção das variações de altura determinaram-se as concentrações de urânio, tório e potássio e a taxa de exposição em superfície.

A taxa de contagem corrigida pode ser convertida para concentração na superfície terrestre de acordo com a seguinte expressão (IAEA, 1991):

$$
C=\frac{N}{S}
$$

Onde: $C=$ concentração dos radioelementos $(\%$ de $\mathrm{K}, \mathrm{ppm}$ de $\mathrm{U}$ e ppm de Th);

$S=$ sensibilidade do equipamento em determinada janela do espectro;

$N=$ Taxa de contagem corrigida

Para calcular a "taxa de exposição" das medidas de contagem total (em $\mu R / h)$ utilizou-se a seguinte expressão (IAEA, 1991): 


$$
E=1,505 K+0,653 e U+0,287 e T h
$$

Onde $K, e U$ e $e T h$ as concentrações aparentes determinadas.

Os valores de sensibilidade do equipamento utilizados na conversão de taxas de contagens para concentração em superfície, foram estabelecidos através de teste realizado na já citada pista de calibração dinâmica e num trecho voado sobre a água (lagoa) no dia 06 de junho de 2007. Na ocasião utilizou-se ao longo da linha e na lagoa um espectrômetro gama com medidas na superfície. Esse equipamento (Exploranium GR 320) é um gamaespetrômetro de 256 canais, com detector de iodeto de sódio ativado a tálio que faz leituras em concentração e de taxa de contagem. Os valores de sensibilidade foram determinados relacionando as medidas do espectrômetro terrestre com as do espectrômetro aerotransportado. As leituras em voo foram realizada em uma altura aproximada de 100 metros. A tabela abaixo informa os valores de sensibilidades utilizados na conversão para concentração nesse trabalho.

Tabela 5.7 - Sensibilidade do sistema

(Fonte: Relatório do Projeto Aerogeofísico Barra da Estiva-Tremedal, CBPM).

\begin{tabular}{|l|l|}
\hline Canal Radiométrico & Sensibilidade (S) \\
\hline Contagem Total & $171,14 \mathrm{cps} / \mu \mathrm{R} / \mathrm{h}$ \\
\hline Potássio & $63,44 \mathrm{cps} / \%$ \\
\hline Urânio & $8,80 \mathrm{cps} / \mathrm{ppm}$ \\
\hline Tório & $3,59 \mathrm{cps} / \mathrm{ppm}$ \\
\hline
\end{tabular}




\subsubsection{Fluxo do processamento}

Baseado nas calibrações e correções citadas nas seções anteriores segue abaixo a sequencia de processamento utilizado nos dados desse trabalho, bem como algumas informações adicionais quando necessário.

- Correção do tempo morto.

- Filtro passa baixa: para reduzir ruídos de alta frequência utilizou-se filtros passa-baixa de 7 segundos para os dados da janela do uranio e 5 segundos para as demais janelas, exceto a janela de radiação cósmica que utilizou-se passa-baixa de 30 segundos.

- Correção da radiação cósmica de fundo e radiação de fundo da aeronave e equipamentos.

- Correção do radônio atmosférico: para determinar os valores do efeito do radônio atmosférico $\left(U_{r}\right)$ aplicou-se filtro passa baixa de 100 segundos nos dados da janela do urânio dos detectores voltados para cima e nos dados da janela do urânio e tório dos detectores voltados para baixo. Foi testado também filtro passa-baixa de 200 segundos nesses dados (apêndice I).

- Correção do efeito Compton.

- Correção de altimetria.

- Conversão para concentração de elementos.

- Interpolação dos valores de concentração e taxa de exposição: Os valores de concentração determinados ao longo da linha para cada um dos 88 testes foram então, interpolados para coordenadas $\mathrm{X}$ e $\mathrm{Y}$ fixas cada ponto a 80 metros ao longo da linha de 8 quilômetros (101 
pontos). Como não houve muita variação na velocidade da aeronave, até como consequência da baixa variação topográfica, essa distância entre os pontos foi definida como a média das distâncias entre as amostras de todas as leituras. A taxa de amostragem do equipamento é uma amostra por segundo, consequentemente a velocidade média de aquisição foi de $80 \mathrm{~m} / \mathrm{s}$ ou $288 \mathrm{~km} / \mathrm{h}$. A altura de voo corrigida média foi de 81 metros.

Para determinar as concentrações de potássio, urânio equivalente, tório equivalente e taxa de exposição, utilizou-se a extensão de processamento de dados radiométricos do software Geosoft Oasis Montaj versão 6.1. 


\section{RESULTADOS}

\subsection{Perfis das taxas de contagens médias}

As figuras 6.1, 6.2, 6.3, 6.4 e 6.5 apresentam perfis com os valores médios de contagens por segundo (cps) dos 88 testes para cada ponto com os desvios padrões da média: janelas do urânio, tório, potássio, contagem total e urânio (upward) respectivamente. Os valores foram somente corrigidos do tempo morto.

Nos perfis, o trecho entre os pontos 60 e 70 possuem contagens muito baixas, pois essa região é cortada por um corpo de água (figura 5.1). Após as correções de radiação cósmica, radiação de fundo e radônio atmosférico as contagens nesse local deverão ficar próximas de zero.

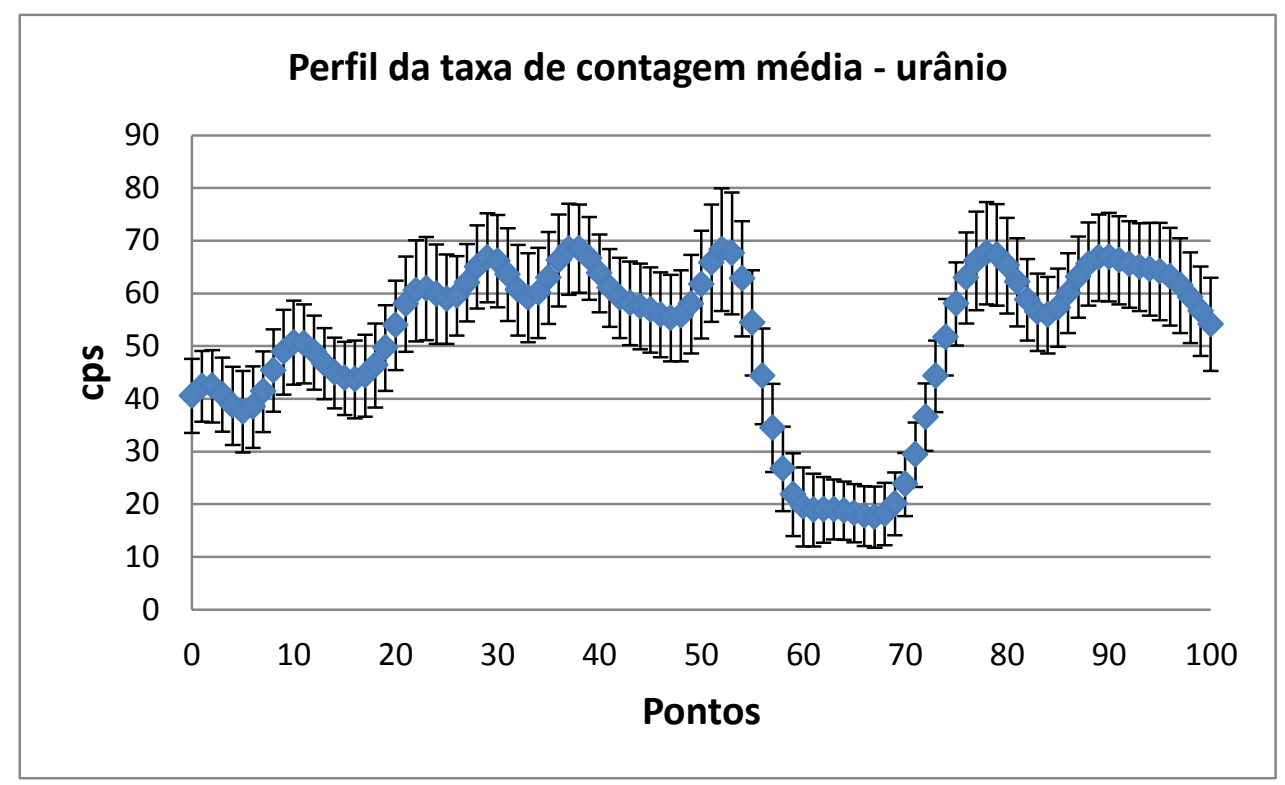

Figura 6.1 - Perfil da taxa de contagem média referente à janela do urânio. 


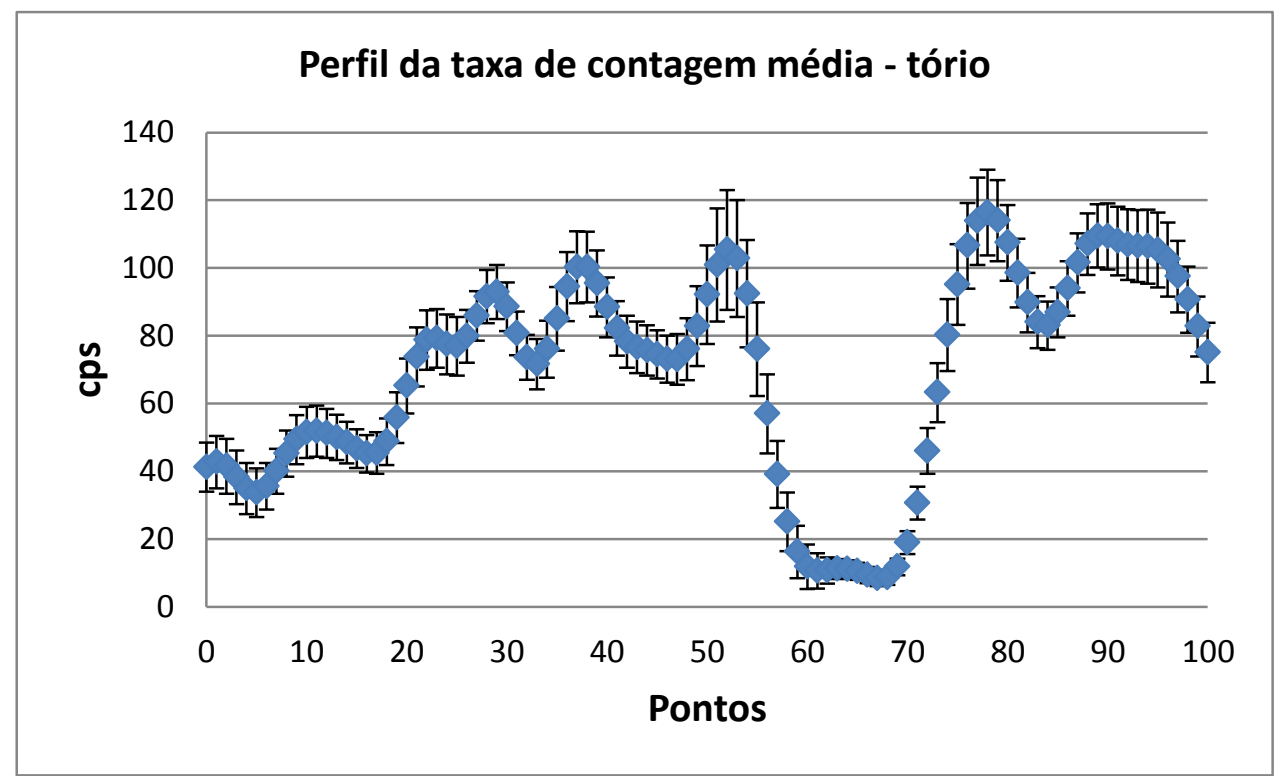

Figura 6.2 - Perfil da taxa de contagem média referente à janela do tório.

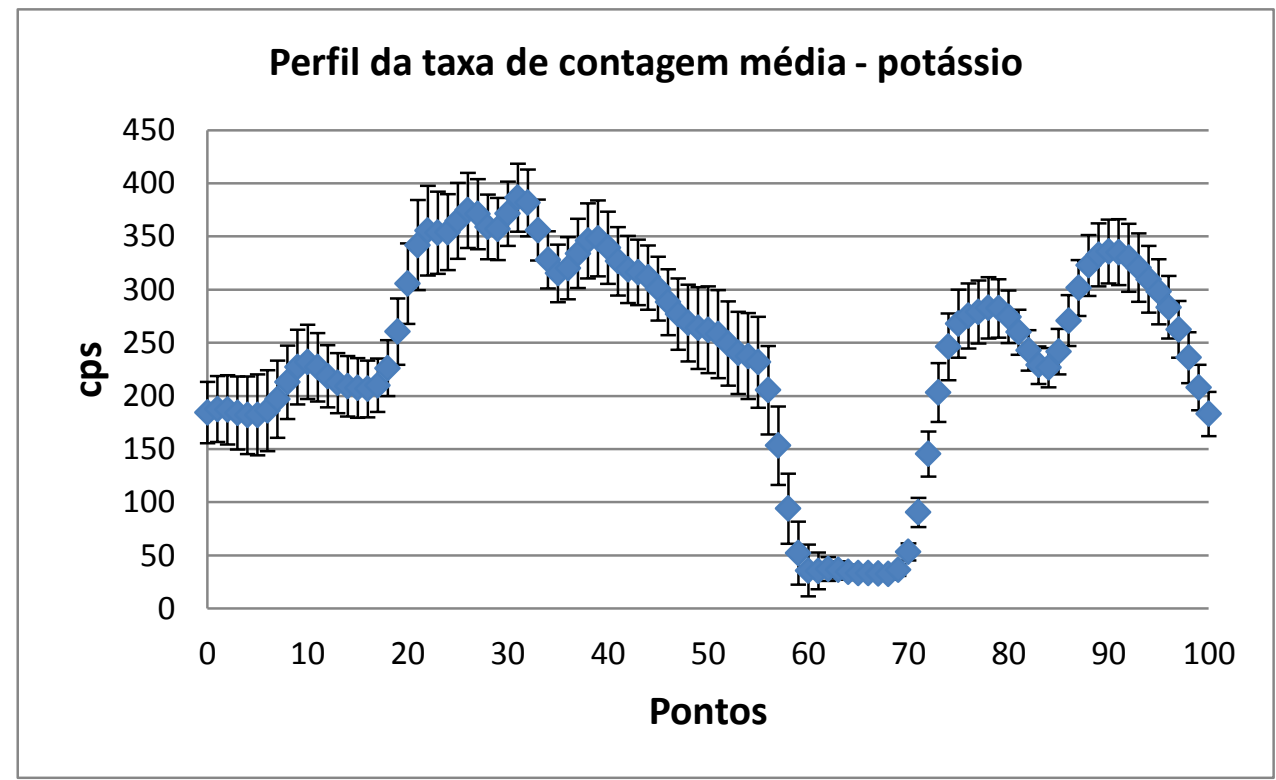

Figura 6.3 - Perfil da taxa de contagem média referente à janela potássio. 


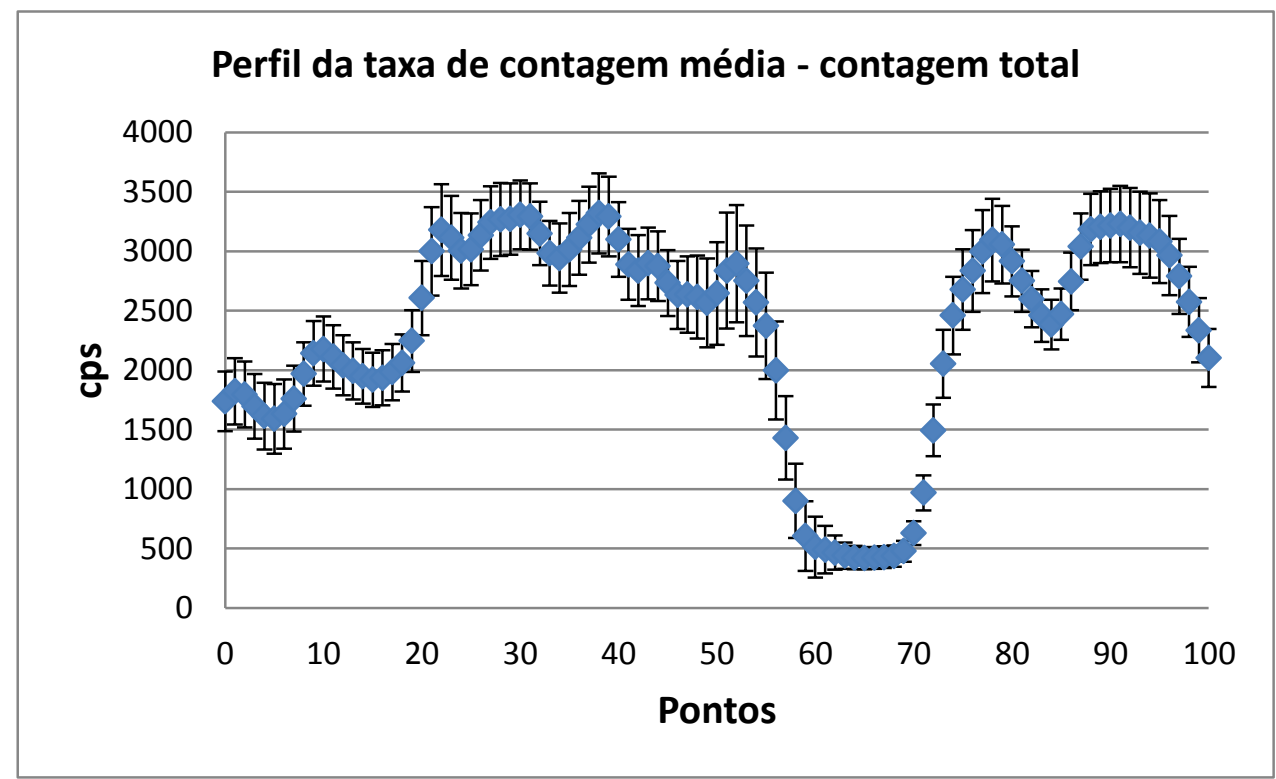

Figura 6.4 - Perfil da taxa de contagem média referente à janela de contagem total.

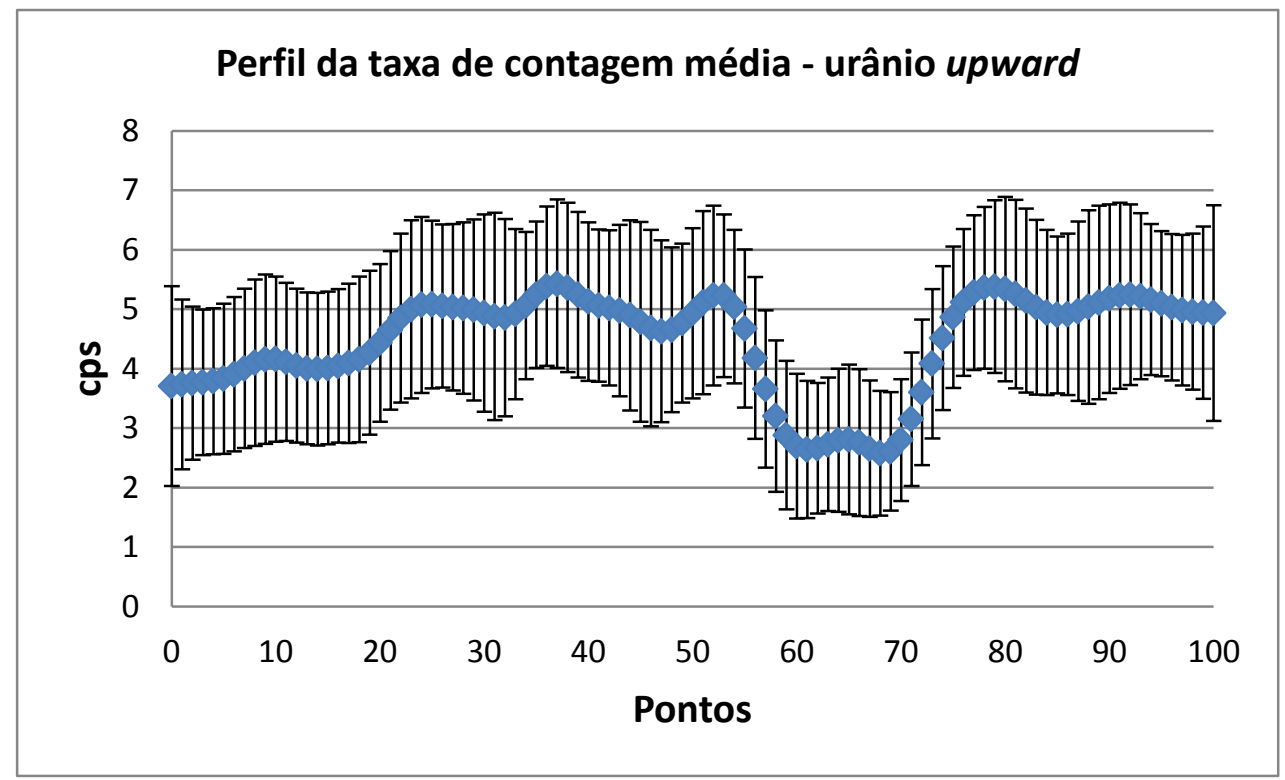

Figura 6.5 - Perfil da taxa de contagem média referente à janela do urânio (upward). 
$\mathrm{Na}$ figura 6.5, embora os valores sejam referentes às medidas no detector voltado para cima, nota-se uma correlação com as medidas das janelas do detector voltado para baixo, justificando a necessidade do cálculo dos coeficientes $a_{1}$ e/ou $a_{2}$ determinados na seção 5.1.3.1.

Percebe-se ainda que os desvios padrões da janela do urânio variam mais que os demais, isso indica que a janela desse elemento esta mais susceptível às variações diárias de radônio atmosférico.

\subsection{Perfis de concentrações médias}

As concentrações dos elementos e a taxa de exposição foram determinadas de duas formas: uma pequena modificação na correção de radônio atmosférico para cada uma. Na primeira utilizou-se para o calculo de $U_{r}$ o coeficiente $a_{1}$ igual a zero e na segunda maneira com $a_{2}$ igual a zero.

As figuras 6.6, 6.7, 6.8 e 6.9 apresentam perfis comparativos para as concentrações médias de urânio equivalente, tório equivalente, potássio e taxa de exposição quando $a_{1}$ igual à zero e quando $a_{2}$ igual à zero. 


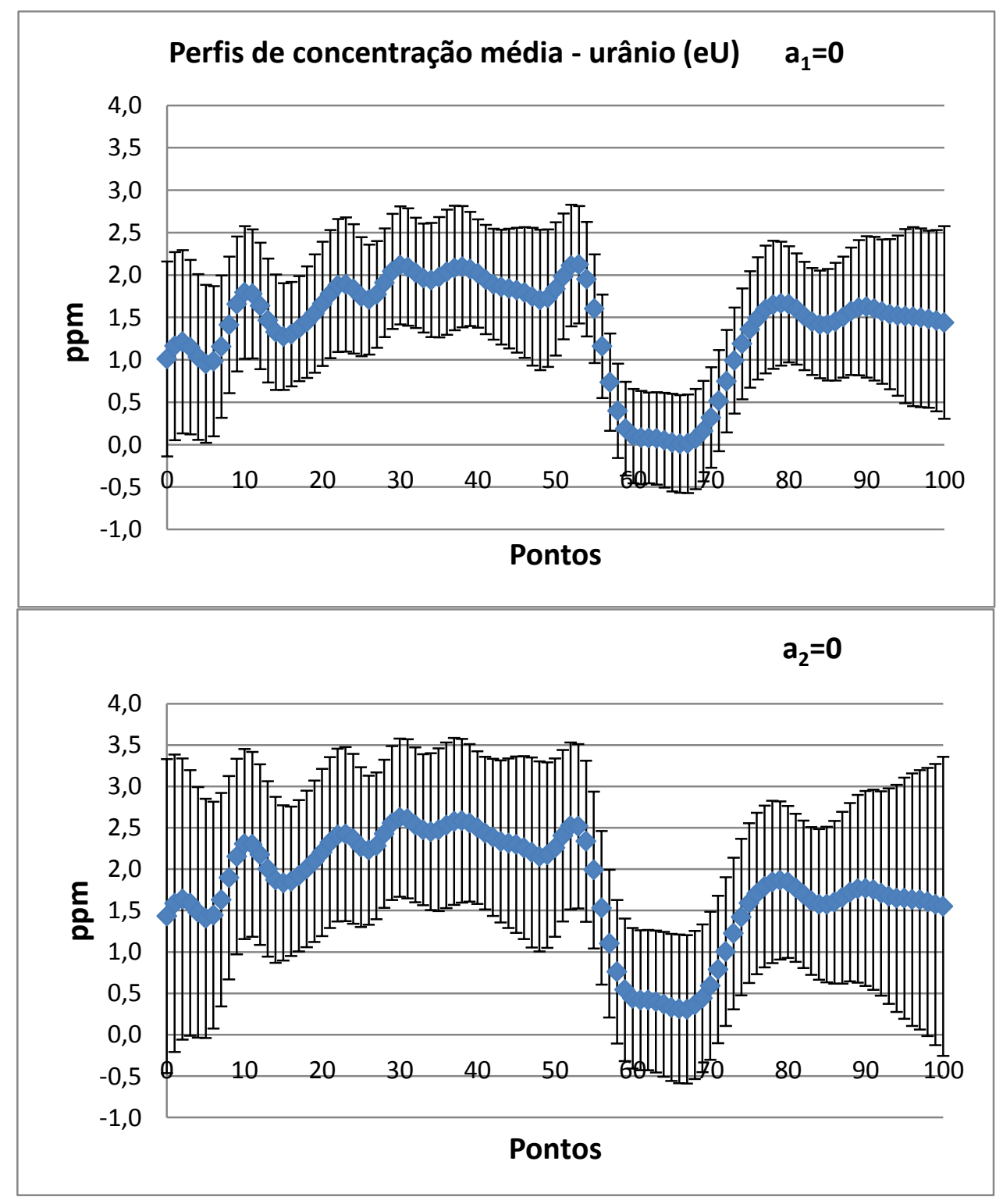

Figura 6.6 - perfis comparativos de concentração média de urânio equivalente. 


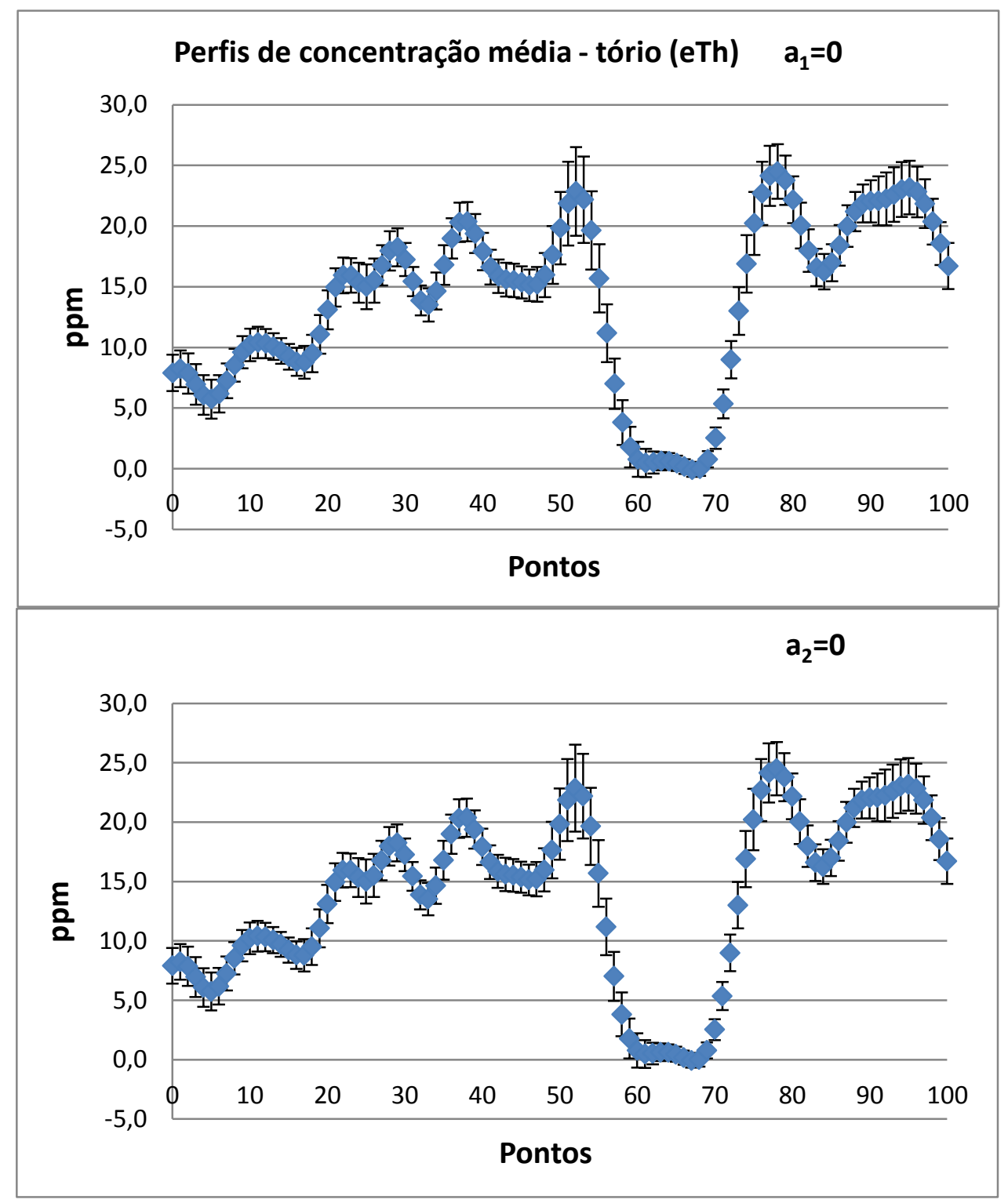

Figura 6.7 - perfis comparativos de concentração média de tório equivalente. 


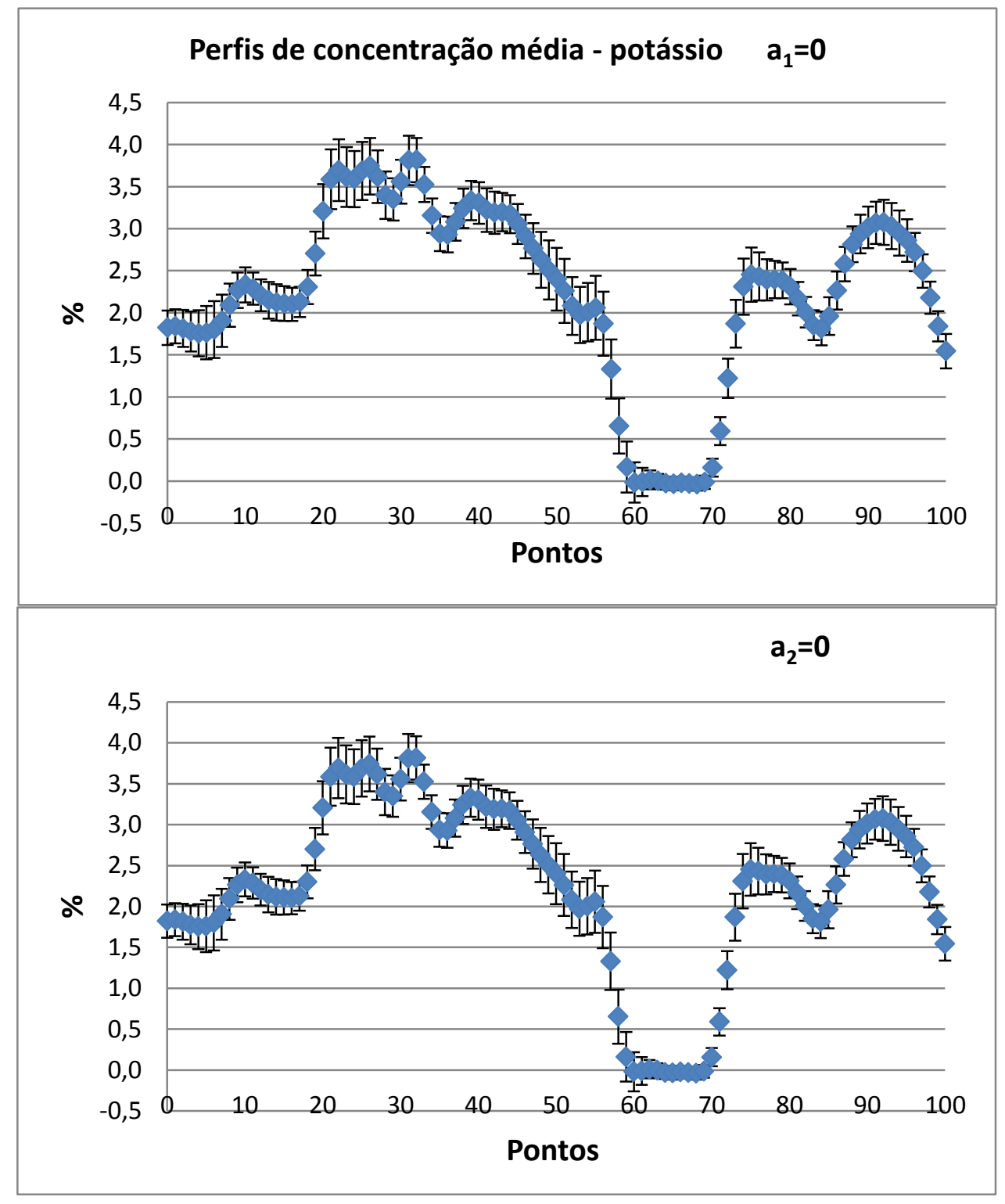

Figura 6.8 - perfis comparativos de concentração média de potássio. 


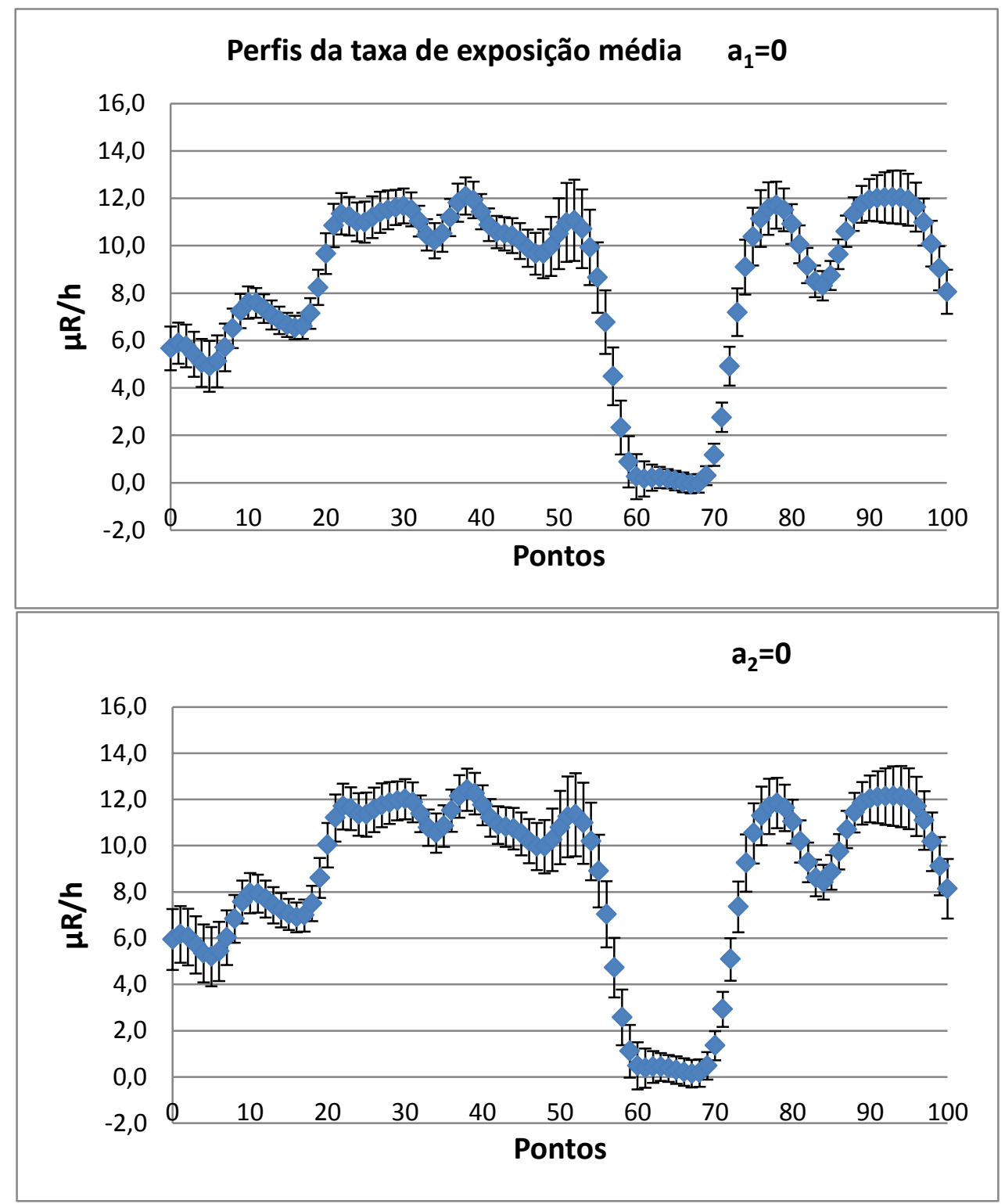

Figura 6.9 - perfis comparativos de taxa de exposição média.

As comparações dos perfis indicam pouca diferença entre escolher o uso de $a_{1}$ igual a zero ou com $a_{2}$ igual a zero, exceto para os perfis de urânio equivalente. Duas características chamam a atenção, quando comparamos os perfis: o desvio padrão da média e a concentração referente ao trecho sob o corpo de água (entre os pontos 60 e 70). 
As barras do desvio padrão da média para a situação onde $a_{2}$ igual a zero são maiores que para a outra situação. Analisando as expressões abaixo definidas na seção 5.1.3.1 entende-se o porquê dessa diferença.

Quando, $a_{2}=0$ :

$$
U_{r}=\frac{u-a_{1} U}{a_{u}-a_{1}}
$$

Quando, $a_{1}$ :

$$
U_{r}=\frac{u-a_{2} T}{a_{u}-a_{2} a_{t}}
$$

$U$ e $T$ são referentes as medidas nas janelas do urânio e tório corrigidas de radiação de fundo e radiação cósmica. O erro associado a $U$ é superior ao erro associado a $T$ (figuras 6.1 e 6.2), logo o erro no valor de concentração para o urânio equivalente também será maior.

Para as demais concentrações, como:

$$
\begin{aligned}
& K_{r}=a_{K} U_{r} \\
& T_{r}=a_{T} U_{r}
\end{aligned}
$$

E os valores de $a_{K}$ e $a_{T}$ são muito pequenos com relação à $U_{r}$ resultará em valores muito próximos para as duas situações. Consequentemente a taxa de exposição também terá uma leve diferença: consequência dos valores de concentração de urânio equivalente utilizados no seu cálculo.

Em trechos sob a água: lagos, rios etc, os valores de concentração tendem a zero por conta do bloqueio parcial da água dos raios gama. Sendo assim, os valores de concentração de urânio equivalente determinados em $a_{1}$ 
igual a zero, são mais coerentes. Quando $a_{2}$ igual a zero, o perfil para as concentrações de urânio em geral ficaram um pouco superiores com relação à outra situação $\left(a_{1}=0\right)$.

Nas próximas seções foram utilizados dados de concentração determinado com $a_{1}$ igual a zero.

Importante ressaltar que os valores de concentrações para cada elemento: urânio equivalente, tório equivalente e potássio ficaram de acordo com o esperado, tendo em vista a geologia do local.

\subsection{Perfis comparativos diários de concentração de urânio equivalente}

Para avaliar as concentrações de urânio equivalente determinadas para testes individuais em dias específicos, como por exemplo, quando as taxas de contagens ficaram acima da média, foram comparados testes individuais com a média de todos os testes. Essa análise foi realizada somente nos dados de urânio equivalente, uma vez que os dados diários de tório e potássio variam pouco, como mostrado na seção anterior. Nesse processo foi detectado dois testes com problemas de equipamento: valores muito abaixo do esperado para a janela do urânio no detector voltado para cima (apêndice III).

A figura 6.10 apresenta perfis do teste realizado em 14/05/2008 (preto), um dia típico para todo o levantamento, ou seja, os valores de taxa de contagem para a janela do urânio do detector principal e do detector voltado para cima (upward) estão bem próximos dos valores médios (azul). 
Consequentemente os valores em concentração (eU) apresentaram também uma concentração bem próxima da média de todos os testes.

A incerteza nos valores de concentrações para um teste individual foi calculado sem considerar os erros associados aos coeficientes de correção da radiação cósmica e radiação de fundo da aeronave, coeficientes de atenuação atmosférica e os erros associados à sensibilidade do equipamento, uma vez que eles não constam no relatório do projeto do Aerogeofísico Barra da EstivaTremedal. Entretanto, os erros associados a correção do radônio atmosféricos são os mais significatívos e foram devidamente considerados nesse trabalho. 


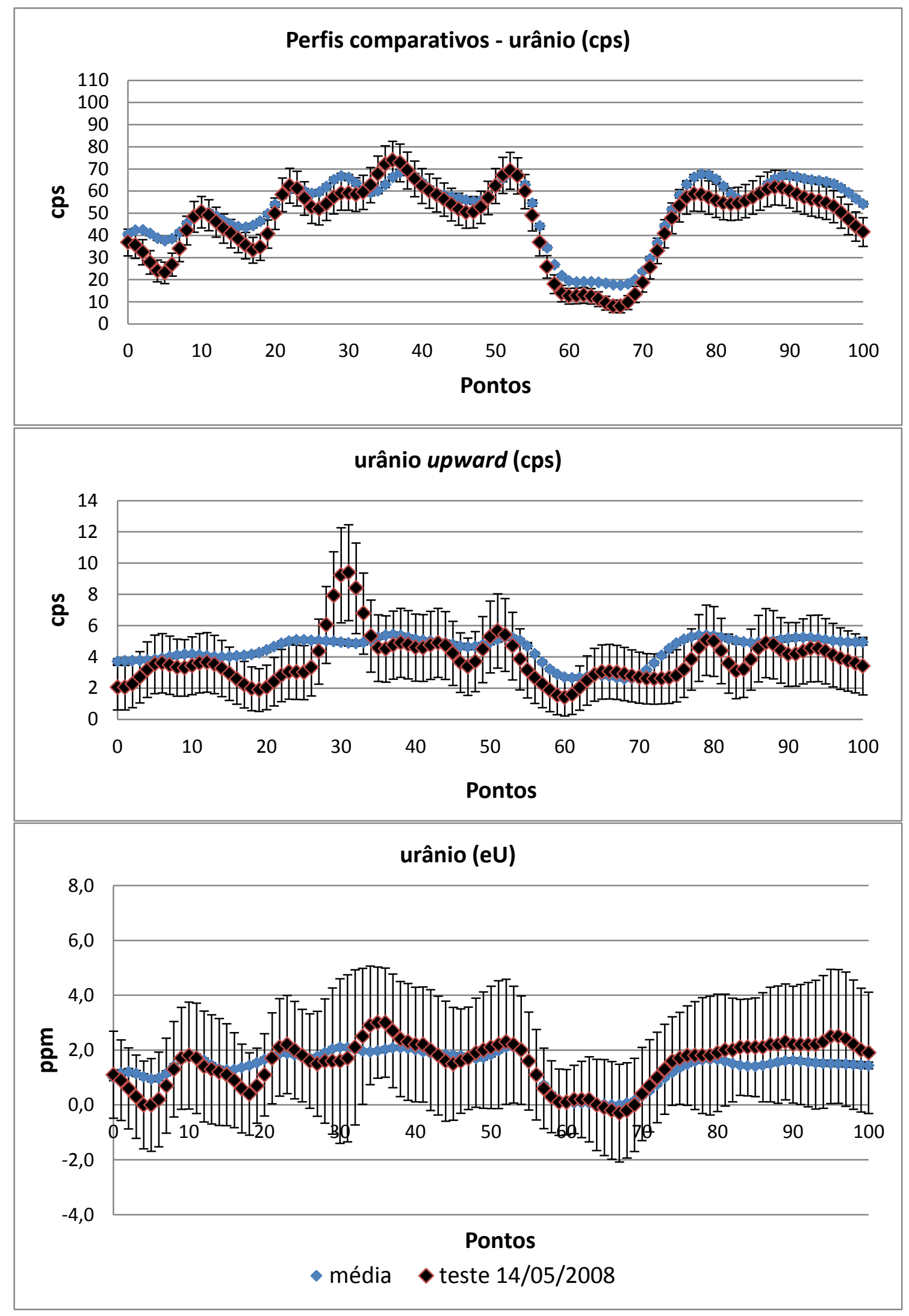

Figura 6.10 - Perfis comparativos diários de concentração de urânio equivalente (14/05/2008). 
Por outro lado a figura 6.11 apresenta o perfil referente a um teste onde as contagens nas janelas do urânio ficaram acima da média. Os valores de concentração em alguns pontos ficaram devidamente corrigidos: entre os pontos 80 e 100. No entanto, de um modo geral o perfil para esse teste, que foi realizado no dia 24/04/2008, ficou com uma tendência a valores inferiores à média. 


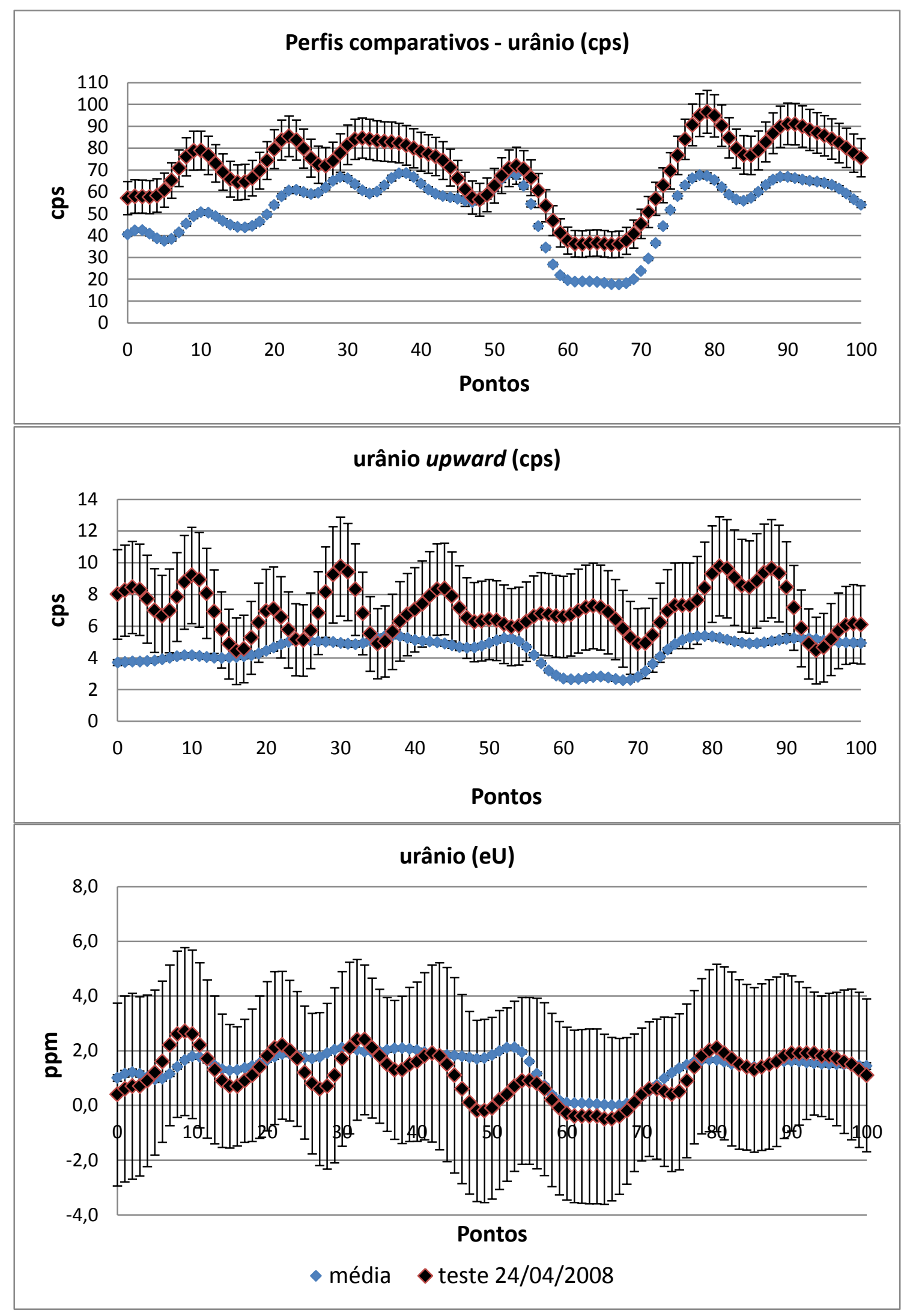

Figura 6.11 - Perfis comparativos diários de concentração de urânio equivalente (24/04/2008). 
De um modo geral, o fator determinante para que as variações diárias referentes ao radônio atmosférico sejam devidamente corrigidas é como as medidas na janela do detector voltado para cima estão relacionadas com as medidas dos detectores voltados para baixo, sejam elas na janela do urânio ou na do tório. Por exemplo: se as medidas das taxas de contagem estiverem altas em ambos os detectores em um determinado dia, mas relacionadas de acordo com os valores $b_{t}, b_{u}, a_{u}$ e $a_{t}$ no que diz respeito à parcela na medida referente ao radônio atmosférico, a correção será de qualidade. Para isso o radônio atmosférico e seus produtos (filhos) deverão ter comportamentos similares na atmosfera, tanto na altura que foi realizado o teste de repetibilidade radiométrica como na do teste de radiação gama atmosférica. Se por algum motivo como precipitação pluviométrica as relações entre os detectores voltados para cima e os detectores voltados para baixo no levantamento forem diferentes das relações determinadas no teste de calibração dos detectores voltados para cima (altura superior a 700 metros) a correção de radônio atmosférico não será realizada de forma correta.

\subsection{Perfil de concentração média de urânio equivalente sem correção de radônio atmosférico.}

A correção de radônio é uma das etapas mais importantes no processo de determinação das concentrações a partir de taxa de contagens obtidas em gamaespectrómetros aerotransportados. A sua não correção ou uma correção

indevida pode levar a obtenção de valores falsos de concentração em 
superfície, sobretudo nas de urânio equivalente. A figura 6.12 apresenta um perfil comparativo entre as concentrações médias de urânio (eU), com e sem a correção de radônio atmosférico. Em vermelho o perfil dos valores médios de concentração de todos os testes, não corrigido do radônio atmosférico e em azul o perfil médio dos valores corrigidos.

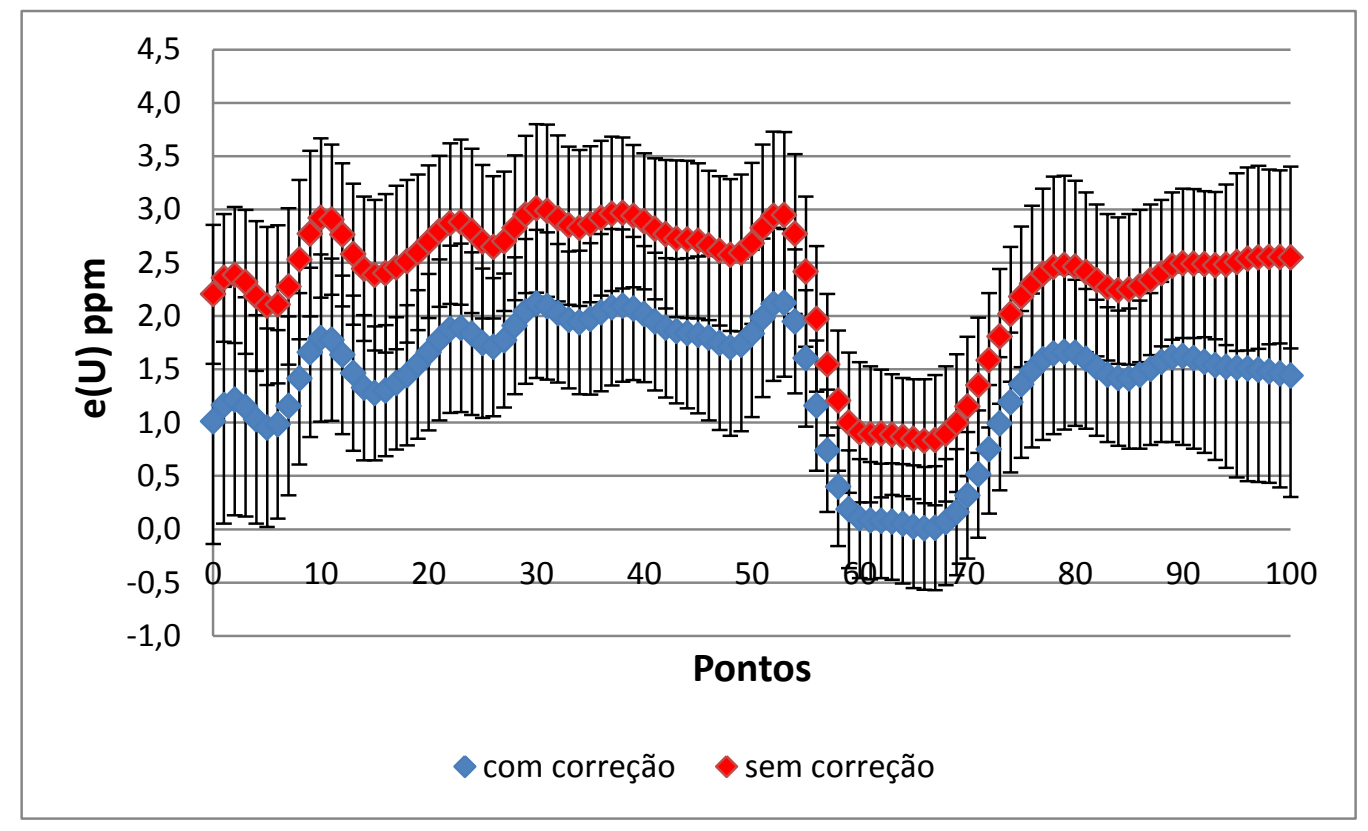

Figura 6.12 - perfil comparativo de concentração média de urânio equivalente com e sem correção de radônio atmosférico. 


\section{CONCLUSÕES}

Apesar das medidas de taxa de contagem referente à janela do urânio adquirido com espectrômetro aerotransportado apresentarem variações diárias ao longo do período do levantamento, os perfis em concentração de urânio equivalente individuais mostraram coerência com a média de todos os perfis. Isso demonstra que a correção de radônio atmosférico utilizando detectores extras voltados para cima, é eficiente na remoção da parcela da atividade gama dos radionuclídeos filhos do ${ }^{222} \mathrm{Rn}\left({ }^{214} \mathrm{Bi}\right.$ e $\left.{ }^{214} \mathrm{~Pb}\right)$, uma vez que esses detectores forem devidamente calibrados. Caso a correção de radônio atmosférico não seja feita, ou feita de forma incorreta os valores de concentração de urânio equivalente podem ser superestimados, podendo influenciar significativamente em uma interpretação geofísica.

Os perfis de concentrações de tório equivalente e potássio não variaram tanto quando os perfis de concentração de urânio equivalente. Isso ocorre, pois os produtos filhos do ${ }^{222} \mathrm{Rn}$ não produzem tanta influência nas suas janelas espectrais.

A utilização do coeficiente de calibração dos detectores voltados para cima $a_{1}$ sendo nulo, determinado pelo método proposto por Grasty \& Hovgaard (1996) mostrou ter maior coerência que quando $a_{2}$ igual à zero. Mas isso somente na determinação das concentrações de urânio equivalente, tendo em vista que para as concentrações de tório equivalente e potássio apresentaram valores muito próximos para as duas situações.

Como as medidas desse trabalho foram realizadas levando em consideração as normas da Agencia Internacional de Energia Atômica (IAEA) 
com relação às condições meteorológicas ideais para um aerolevantamento gamaespectrométrico, não foi possível avaliar situações mais extremas de variações de raios gamas atmosféricos como leituras logo após uma chuva ou garoa, que pelo processo de washout ocorre a precipitação de partículas radioativas, aumentado a atividade radioativa na superfície. 


\section{REFERÊNCIAS}

BECK, H.L. - 1974 - Gamma Radiation From Radon Daughters in the Atmosphere. Journal of Geophysical Research, Vol. 79, n 15: 2215-2221.

BEVINGTON, P.R. - 1969 - Data reduction and error analysis for the physical sciences. McGRAW-HILL BOOK COMPANY: 93-118.

BILLINGS, S.D. - 1998 - Geophysical Aspects of Soil Mapping Using Airborne Gamma-Ray Spectrometry. Department of Crop Sciences Faculty of Agriculture the University of Sydney. Canberra, Australia, 293 pp.

CPRM - Carta Geológica do Brasil ao Milionésimo. Folha SD.24 - Salvador. Rio de Janeiro.

DICKSON, B. - 2001 - Improving the quality of aerial gamma-ray surveys. ASEG $15^{\text {th }}$ Geophysical Conference and Exhibition. Brisbane, Australia.

ERDI-KRAUSZ, G.; MATOLIN, M., MINTY, B.; NICOLET, J.P.; REFORD, W.S. \& SCHETSELAAR, E. - 2003 - Guidelines for radioelement mapping using gamma ray spectrometry data. International Atomic Energy Agency $n^{\circ} 1363$, Viena, Austria, $179 \mathrm{pp}$.

GRASTY, R.L. \& MINTY, B.R.S. -1995 - A guide to the technical specifications for airborne gamma-ray surveys. Australian Geological Survey Organization, Record 1995/60, Canberra, Australia, 89 pp. 
GRASTY, R.L., \& HOVGAARD, J. - 1996 - The calibration of upward detectors in gamma ray surveys. Expanded abstracts, Society of Expl. Geophysicists annual meeting, Denver: 1425 - 1442.

GILMORE, G. \& HEMINGWAY, J. -1995 - Practical Gamma-Ray Spectrometry. Jonh Wiley \& Sons Ltd, Chichester, Inglaterra .

GUITERAS, L.F. Radon generation, entry and accumulation indoors. PhD thesis, Grup de Física de les Radiacions - Universitat Autònoma de Barcelona. Barcelona, Espanha, 189 pp.

GARVER, E. \& BASKARAN, M. -2004 - Effects of heating on the emanation rates of radon-222 from a suite of natural minerals. Applied Radiation and Isotopes 61: 1477-1485.

GAT, J.R.; ASSAF, G. \& MIKO, A. Disequilibrium between the Short-Lived Radon Daughter Products in the Lower Atmosphere Resulting from Their Washout by Rain. Journal Geophysical Research, Vol. 71, n 6: 1525-1535.

JACOBI, W. \& ANDRÉ, K. - 1963 - The Vertical Distribution of Radon 222, Radon 220 and Their Decay Products in the Atmosphere. Journal Geophysical Research, Vol. 68, n 13: 3799-3813.

KOGAN, R.M.; NAZAROV, I.M. \& FRIDMAN, D. - 1971 - Gamma Spectrometry of Natural Environments and Formations. Israel Program for Scientific Translations. Jerusalem, Israel.

MARES, S. - 1984 - Introduction to Applied Geophysics. D. Reidel Publishing Company, Praga, República Tcheca. 
MINTY, B.R.S.; LUYENDICK, A.P.J \& BRODIE, R.C. - 1997 - Calibration and data processing for airborne gamma ray spectrometry. AGSO Journal of Australian Geology \& Geophysics, Vol 17 n²: 51-62.

MOSES, H.; STEHNEY A.F. \& LUCAS, H.F. - 1960 - The Effect of Meteorological Variables upon the Vertical and Temporal Distributions of Atmospheric Radon. Journal Geophysical Research, Vol. 65, n 4: 1223-1238.

TELFORD, W.M.; GELDART, L.P. \& SHERIFF, R.E. -1990 - Applied Geophysics - Second Edition. Cambridge University Press, Cambridge, Inglaterra.

IAEA - 1991 - Airborne Gamma Ray Spectrometer Surveying. Technical Reports Series - International Atomic Energy Agency, $n^{\circ} 323$, Viena, Austria, $94 \mathrm{pp}$.

RAMA, N.B. - 1963 - Study of Atmospheric Washout Process by Means of Radon Decay Products. Journal Geophysical Research, Vol. 68, n 13: 3823 3826.

STERNERT, R.H. - 2008 - Relatório Final do Levantamento e Processamento dos Dados Magnetométricos e Gamaespectrométricos. Consórcio Companhia Baiana de Pesquisa Mineral - Prospectors Aerolevantamentos e Sistemas, Vol I. Rio de Janeiro.

WHITEHEAD, N. \& MUSSELMAN C. - 2005 - Montaj 256-Channel Radiometrics Processing. User guide and tutorial - Radiometrics Processing Extension for Oasis Montaj v6.1, Toronto, Canada, 48 pp. 


\section{APENDICE I - DETERMINAÇAO DO FILTRO PASSA-BAIXA}

$\mathrm{Na}$ etapa de correção do radônio atmosférico utilizou-se filtro passabaixa nas janelas do urânio e do potássio. No caso do urânio na janela dos detectores voltados para baixo e dos detectores voltados para cima. Para determinar qual o "peso" do filtro testaram-se alguns valores. A figura I apresenta perfis comparativos entre filtros passa-baixa de 100 e 200 segundos.

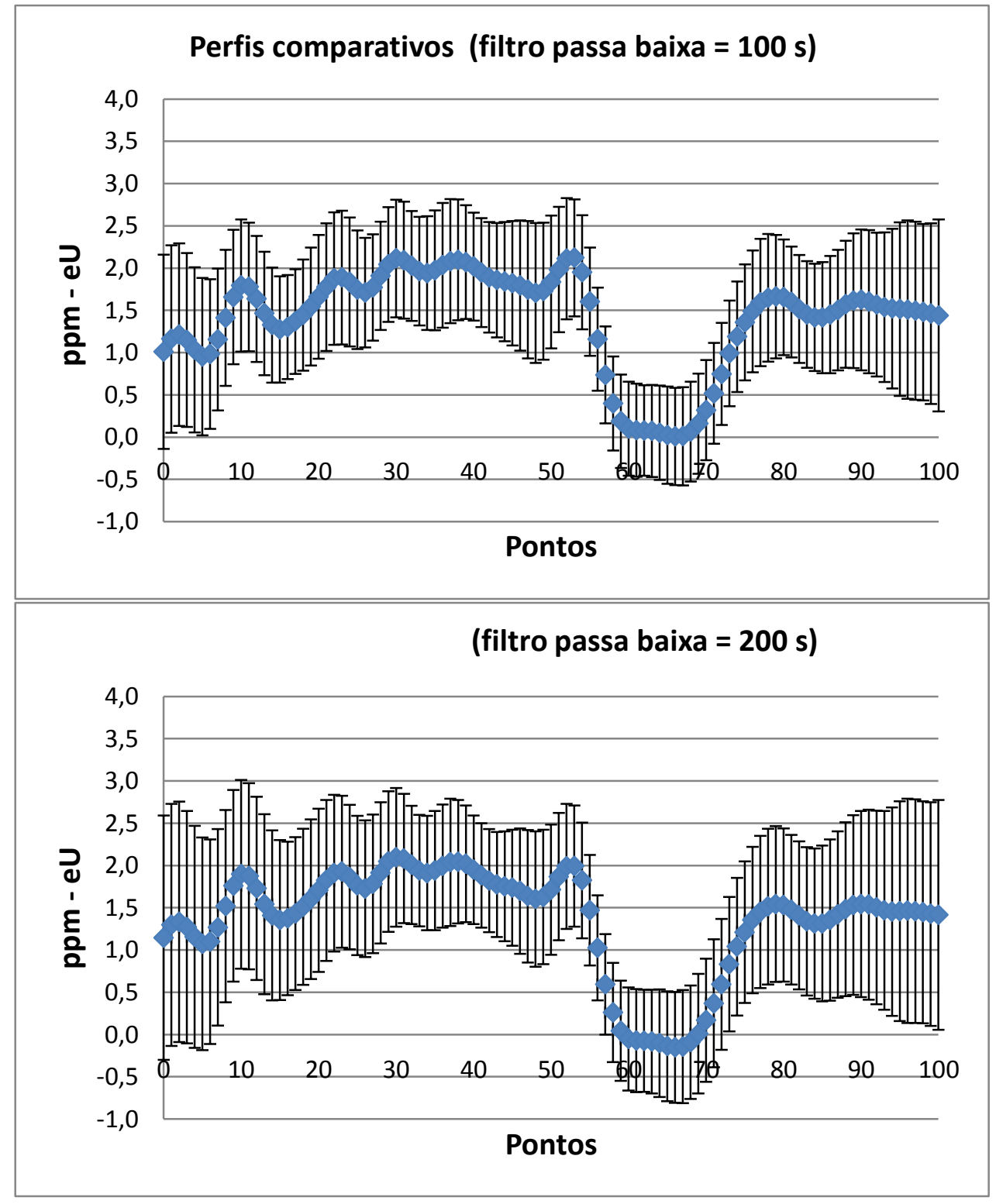

Figura I - Perfis comparativos para determinação do filtro passa-baixa. 
Esses perfis são referentes às concentrações médias de urânio equivalente de todos os testes, ora utilizando filtro passa-baixa de 100 segundos ora de 200 segundos.

Observa-se que na utilização do filtro passa baixa de 200 segundos houve um aumento no tamanho das barras do desvio padrão da média, principalmente nas bordas do perfil. 


\section{APENDICE II - PROBLEMA DE EQUIPAMENTO NO DETECTOR VOLTADO PARA CIMA.}

Dos 88 testes diários de repetibilidade radiométrica utilizados nesse trabalho dois apresentaram problemas por conta de mau funcionamento de equipamento. As medidas de taxa de contagem na janela do urânio nos detectores voltados para cima (upward) eram muito mais baixas que o esperado, ao menos a metade do valor esperado. Isso resultou em concentrações falsas de urânio equivalente. A figura II apresenta os perfis comparativos desses testes com a média de todos os testes. Embora as taxas de contagem na janela do urânio estão coerentes, os valores calculados para a concentração de urânio equivalente estão maiores que os valores esperados. Isso é resultante dos baixos valores das taxas de contagem na janela do urânio dos detectores voltados para cima. Os perfis em azul são referentes aos valores médios para todos os testes e em preto os valores do teste realizado em 29/03/2008. 


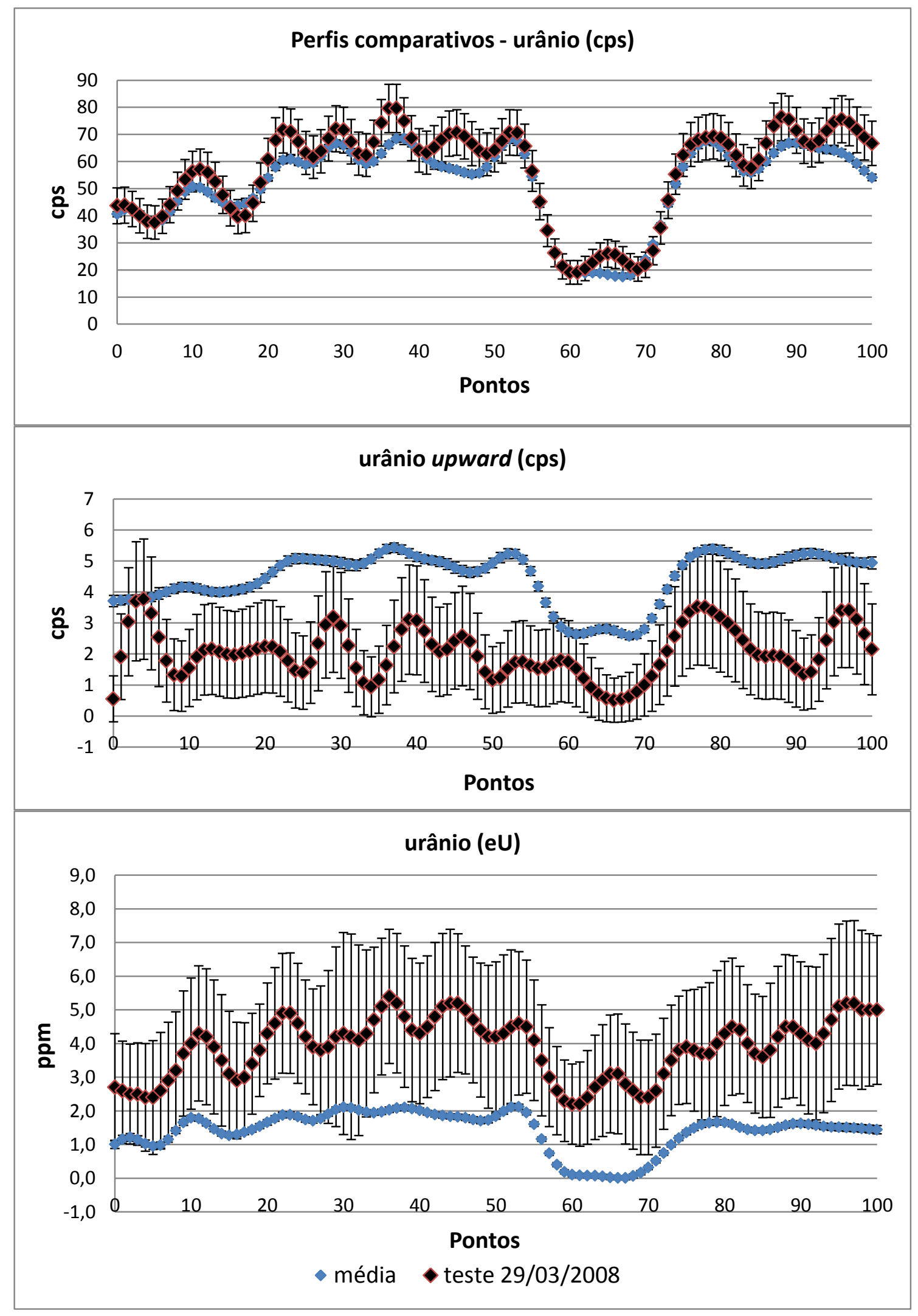

Figura II - Perfil indicando problema no equipamento. 